\title{
Impact of Combined Assimilation of Wind Profiler and Doppler Radar Data on a Convective-Scale Cycling Forecasting System
}

\author{
CHENG WANG, ${ }^{\mathrm{a}, \mathrm{b}}$ Min Chen, ${ }^{\mathrm{b}}$ AND YAODENG $\mathrm{CHEN}^{\mathrm{a}}$ \\ ${ }^{a}$ Key Laboratory of Meteorological Disaster of Ministry of Education (KLME)/Joint International Research Laboratory of Climate and \\ Environment Change (ILCEC)/Collaborative Innovation Center on Forecast and Evaluation of Meteorological Disasters, \\ Nanjing University of Information Science \& Technology, Nanjing, China \\ ${ }^{\mathrm{b}}$ Institute of Urban Meteorology, China Meteorological Administration, Beijing, China
}

(Manuscript received 20 November 2020, in final form 3 December 2021)

\begin{abstract}
The two types of wind observations, profiler and radar radial velocity, have been successfully assimilated into numerical weather prediction (NWP) systems. However, the added value of profiler data, especially from a densely deployed profiler network, is unknown when assimilated together with Doppler radar radial velocity. In this article, two combined assimilation strategies of profilers along with radar radial winds are compared within a convective-scale data assimilation (DA) framework. In strategy I, the profiler data are assimilated with conventional observations to generate an intermediate analysis that acts as a prior for radar data assimilation. In strategy II, both profiler and radar data are considered as storm-scale and assimilated within the same pass. Single- and dual-observation assimilation experiments indicate that for strategy I, the profiler DA improvement can be partly canceled by the potentially negative impact of the assimilation of single-radar radial velocity afterward, particularly when the radial wind is nearly orthogonal to the prevailing wind. For strategy II, important complements are provided when profilers are assimilated within the same pass along with radial winds. The diagnostics for a low-level jet case demonstrate that both strategies facilitate improved analyses and forecasts. But strategy II may bring more moderate analysis increments, which indicate mutual constraints of the profiler and radial winds when assimilated within the same pass. The results obtained in 1-month, retrospective cycling experiments also show that the strategy II outperforms the strategy I with slightly better wind and precipitation forecasts.
\end{abstract}

SIGNIFICANCE STATEMENT: Due to the high spatial-temporal wind information provided by profiler and radar radial velocity measurements, their combined assimilation would be expected to improve wind analysis. To fully utilize dense profiler data and radar radial wind in future operational applications, this study proposes a suitable assimilation strategy. If the profilers are defined as synoptic-scale observations, the profiler and Doppler radar data must be assimilated in different passes to adopt different length and variance scales. Whereas it is more reasonable to use a small background correlation length consistent with the radial velocity and, therefore, assimilate in the same pass if the profiler data are considered to better sample storm-scale features. Single- and dual-observation experiments indicate that profiler data provide important complements, while the assimilation of single-radar radial wind may yield analyzed wind results that do not depict the ground truth. A low-level jet case and a 1-month impact study further show that the combined assimilation strategy of assimilating both profiler and Doppler radar using smaller background correlation lengths enhances the analysis and forecasting of wind, resulting in more accurate accumulated precipitation forecasts.

KEYWORDS: Radars/radar observations; Wind profilers; Numerical weather prediction/forecasting; Data assimilation

\section{Introduction}

A wind profiler radar derives wind information from the Doppler shift in the echoes produced by turbulence in clear air (Andersson and Garcia-Mendez 2002). It was first suggested for real-time atmospheric movement monitoring (Angevine et al. 1998; Adachi et al. 2005; Calpini et al. 2011) with the capability of observing macroscale circulation features at high temporal resolution. Moreover, wind profiler data are believed to potentially improve initial conditions and forecasts because they provide frequent, detailed, and high-quality information

DDenotes content that is immediately available upon publication as open access.

Corresponding authors: Min Chen, mchen@ium.cn; Yaodeng Chen, keyu@nuist.edu.cn throughout the troposphere depth (Bouttier 2001). In past decades, with efforts involving the validation and introduction of profiler networks and their observations, profiler data have been successfully assimilated into several numerical weather prediction (NWP) systems, and positive impacts have been obtained (Bouttier 2001; Benjamin et al. 2004; Ishihara et al. 2006; Zhang et al. 2016). Most of these efforts have focused on individual contributions to the realization of an accurate analysis. It is unknown whether wind profiler data still have any added value when assimilated with radar radial velocity, which is playing an increasingly important role in convective-scale data assimilation (DA) (Weygandt et al. 2002; Tong and Xue 2005; Montmerle and Faccani 2009; Simonin et al. 2014; Lippi et al. 2019).

The assimilation of radial velocity from Doppler radar considerably improves the wind analysis of storm-scale features and has positive impacts on quantitative precipitation forecasts (QPFs) owing to their high spatial and temporal resolution capability of capturing the detailed structure of convections 
(Xiao et al. 2005; Hu et al. 2006; Kain et al. 2010; Rennie et al. 2011; Michelson and Seaman 2000; Gao and Stensrud 2014). Nevertheless, we should note that the radial velocity is the only radial wind component provided by radar instruments. Another component, i.e., tangential velocity (or cross-beam wind), which cannot be directly observed, has usually been less frequently addressed within the radar DA context. Therefore, the radaracquired wind information is incomplete, and the radial velocity DA approach has a limited ability to retrieve the complete wind field, especially in single-Doppler assimilation (Sugimoto et al. 2009). One method to assimilate the tangential velocity was proposed by Chen et al. (2017). They developed an improved Doppler radar radial velocity assimilation operator, by which the tangential velocity could be determined, and both wind components were assimilated. Considering that both radar radial velocity and profiler measurements provide high-spatial- and high-temporal-resolution wind observations, their combined assimilation is expected to improve wind analysis.

The issue of spatial resolution is crucial for convective-scale DA (Gustafsson et al. 2018). Currently, observations collected from a wide variety of broadly and densely deployed networks are required to be assimilated simultaneously within operational convection-allowing DA frameworks. As mentioned by Xie et al. (2011), each observation contains information of the true atmosphere at all scales, among which one category is resolved by given observation networks.

However, the background-error (BE) covariances employed in many DA methods assume decorrelation lengths associated with a fixed scale of motion and lack the ability to reflect the desired multiscales of motion (Hu et al. 2006; Gustafsson et al. 2018). To account for the significant differences in the observation network spacings and the scales that these networks observe, a practical approach of multiscale DA is to perform multiple analysis passes, where broadly distributed observations, such as radiosonde data, are assimilated first, followed by a second analysis pass using comparatively shorter decorrelation lengths to assimilate the highresolution observations, such as radar observations (Xie et al. 2011; Xu et al. 2016; Schenkman et al. 2011). Within each pass, multiplicative tuning factors are applied to the statistical length and variance scales of the BE to empirically adjust the BE covariance dominance at corresponding observation scales (Barker et al. 2012). In most circumstances, multiple analysis passes yield reasonable results. Therefore, assimilating the sparsely distributed conventional observations (e.g., radiosonde) is likely to have larger-scale impacts on analyses and forecasts (Hu et al. 2006; Dong et al. 2011). Whereas the observations with high spatial resolution such as radar data, are usually considered to sample the storm-scale features (Tong et al. 2016).

A wind profiler is characterized by its high vertical resolution but is usually considered to provide horizontal synopticscale information, which is reasonable when considering the implementation of large profiler networks deployed with similar density to radiosondes, such as the National Oceanic and Atmospheric Administration (NOAA) Profiler Network (NPN) (St-James and Laroche 2005; Benjamin et al. 2010), and even relatively small networks, such as the Coordinated WIND profiler network in Europe (CWINDE) (Bouttier 2001). In China, the situation could be different because profilers are not evenly distributed. A large operational profiler network that contains 153 wind profiler radars has been constructed across China in recent decades. Some radars are densely deployed in data-rich regions, such as the BeijingTianjin-Hebei region, Yangtze River Delta, and Pearl River Delta. For example, seven profilers are deployed in Beijing within an area of approximately $100 \mathrm{~km} \times 100 \mathrm{~km}$ (Fig. 1). Therefore, it would be ambiguous to classify profiler measurements as a type of synoptic-scale data. Another question has also been raised regarding the development of a suitable assimilation strategy to fully utilize dense profiler data with radar radial wind data in future operational applications. If the profilers are defined as synoptic-scale observations, then the profiler and Doppler radar data must be assimilated in different passes to adopt different length and variance scales. Conversely, if profilers are considered to measure convectivescale observations, it is sufficient that both profiler and Doppler radar data are assimilated with smaller length and variance scales of BE. Hence, two combined assimilation strategies, namely, PROF_PASS1 and PROF_PASS2 strategies, are proposed to better initialize NWP forecasts at convection-resolving scales. The PROF_PASS1 strategy means profiler data are first assimilated using regular background correlation lengths in Pass I followed by Doppler radar data in Pass II, while the PROF_PASS2 strategy represents the combined assimilation of profiler and radar data using comparatively shorter length and different variance scales in Pass II.

This manuscript addresses the abovementioned questions by assimilating profiler data with the radial velocity at different stages of the multipass DA method. Additionally, the benefits of profiler DA are evaluated. We clarify the general improvements obtained from the assimilation of profiler data and the potential advantages/disadvantages over the assimilation of only Doppler radar data.

The remainder of this paper is organized as follows: a quality control (QC) process of wind profilers in China is introduced and validated in section 2 . The model and DA configurations and experimental setup design are described in section 3 . In section 4 , we quantify the effect of the assimilation of both profiler observations and Doppler radar observations in a series of single- and dual-observation tests, a low-level jet (LLJ) case study and a 31-day period cycling assimilation. The results obtained from sensitivity experiments during assimilation and forecast periods and their quantitative verification based on several statistical scores are examined. Section 5 provides a discussion of the main results and offers suggestions for future studies.

\section{Wind profiler data and quality control}

\section{a. Quality control}

In this study, all profiler wind measurements are subjected to a two-step QC procedure based on the iterated reweighted minimum covariance determinant (IRMCD) of multivariate data (Zhang et al. 2017). The first step (hereafter referred to as QC1) is a blacklisting assessment. If the correlation coefficient between the profiler observations and the model background datasets does not exceed a predefined threshold, e.g., 


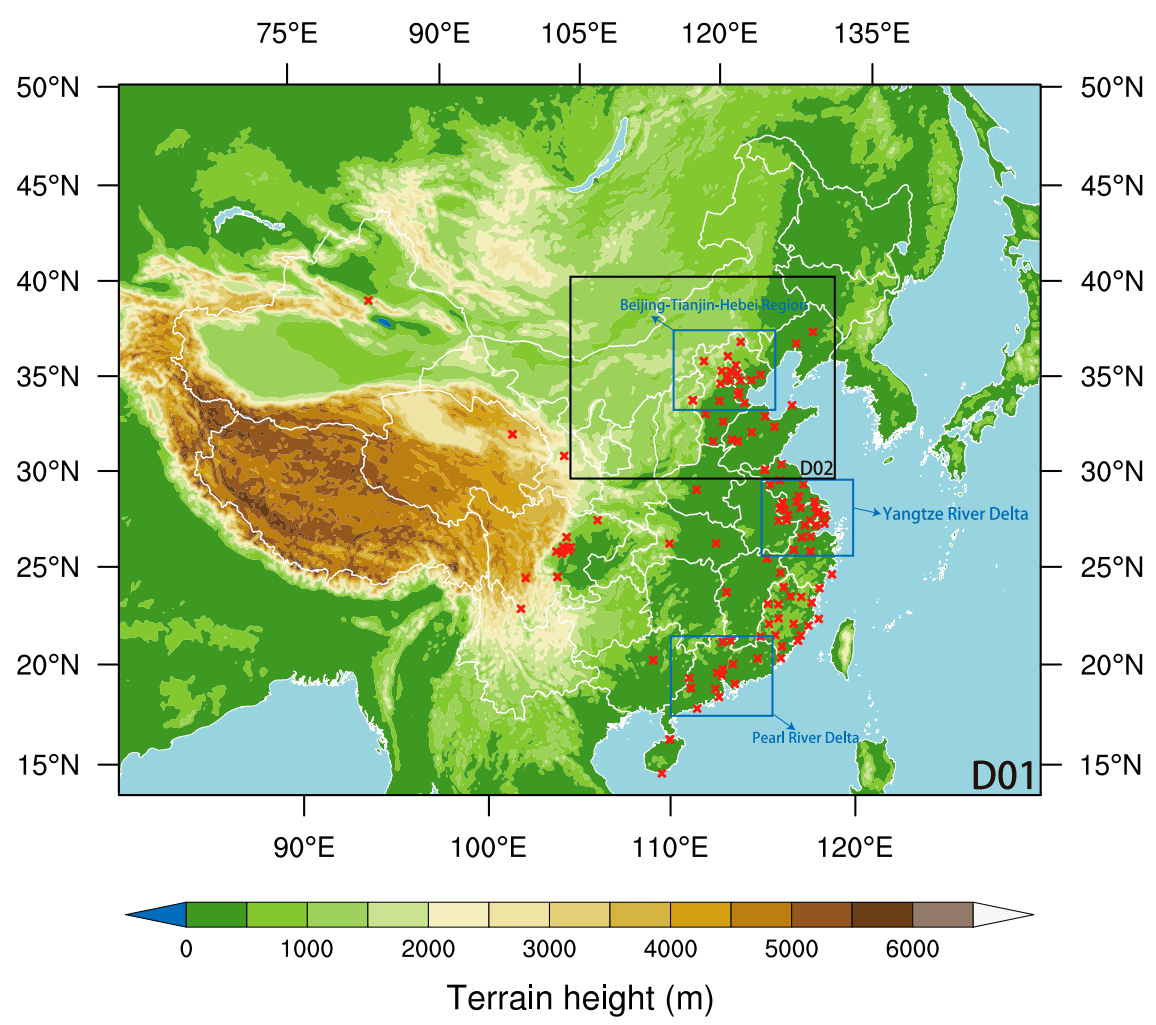

FIG. 1. Spatial distribution of wind profilers.

0.6, as previously defined by Zhang et al. (2017), the corresponding profiler is supposed to be generally unreliable and is blacklisted thereafter. The second step (hereafter referred to as QC2) involves IRMCD-based outlier detection, by which wind profiler observations that have passed the initial blacklisting check but greatly deviate from the model background are rejected. After the QC procedure, the quality of the remaining profiler observations is assumed to be of sufficient for further DA.
To validate the performance of the QC procedure, time series of the profiler observation number and passing rate at each QC step are shown in Fig. 2 for a dataset containing more than 1 month of wind profiler observations from 10 June to 31 July 2018. In general, except for only a few missing data, approximately $3000+$ wind profiler records are collected in every 3-h time slot, among which the passing rate of QC1 is approximately $90 \%$, i.e., $10-15$ profiler stations are entirely removed due to their poor correlation with the model

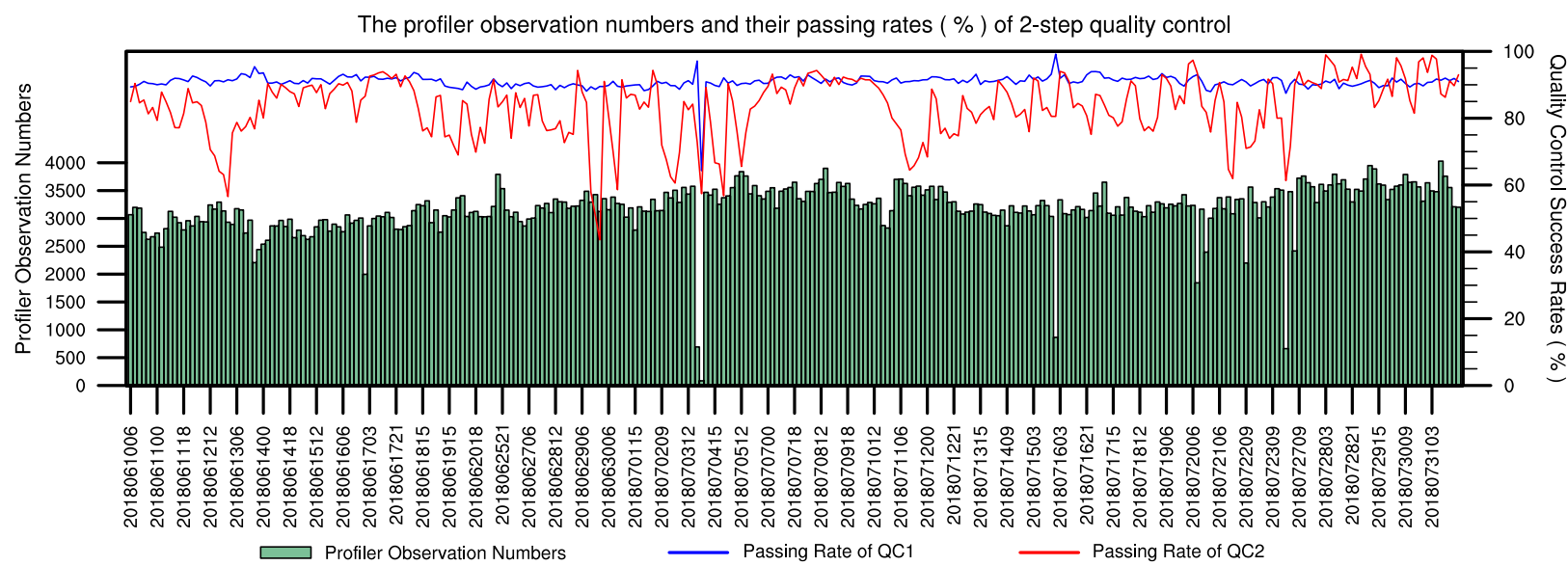

FIG. 2. The profiler observation numbers and their passing rates (\%) of two-step quality control during 0600 UTC 10 Jun-2100 UTC $31 \mathrm{Jul} 2018$. 

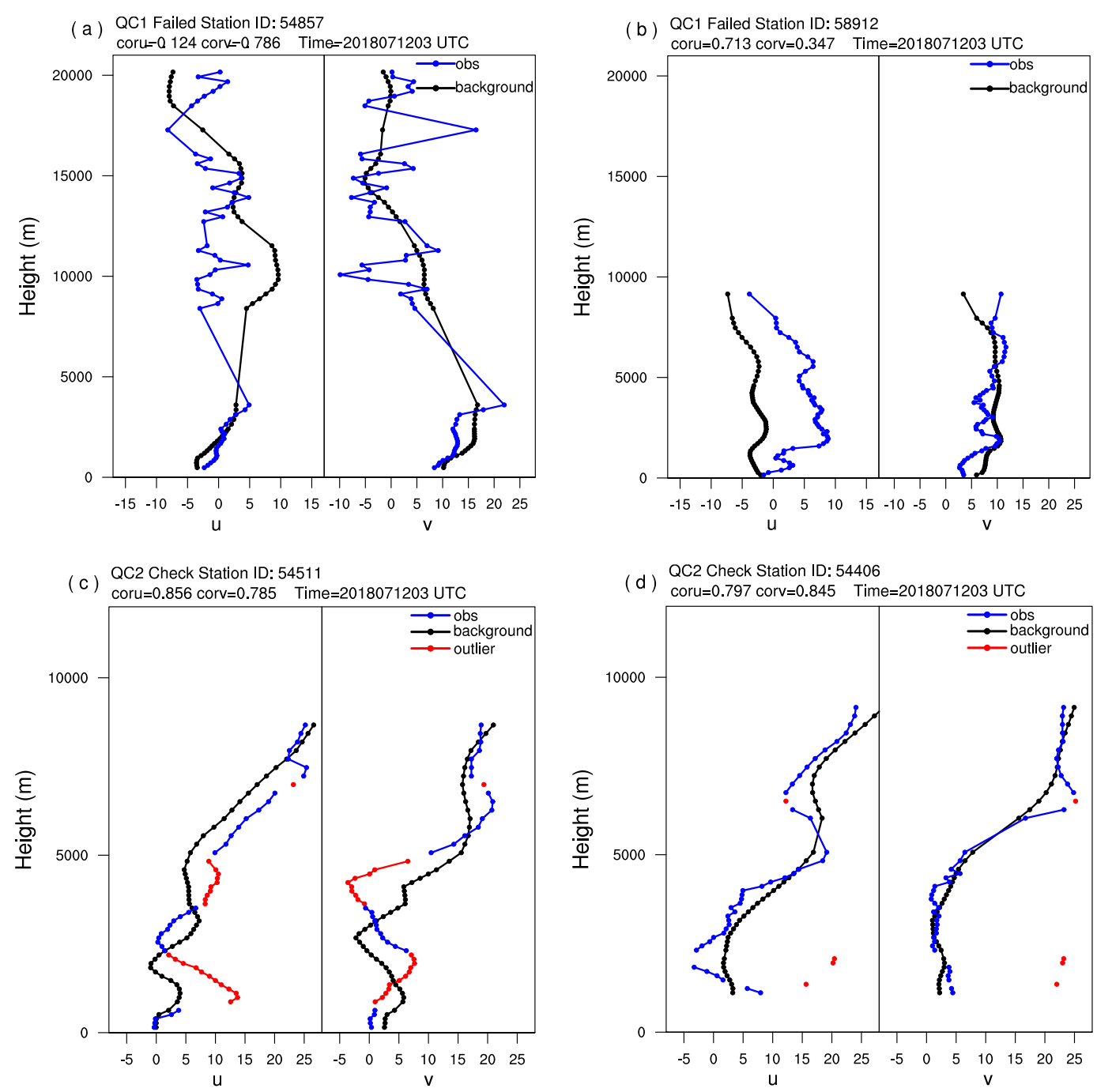

FIG. 3. Profiles of profiler observation (blue/red) and background (black) of $u / v$ components (as well as the correlation coefficients in regard to $u / v$, referred as coru/corv) at 0300 UTC 12 Jul 2018; (a) blacklisted 54857 and (b) blacklisted 58912 profiler station in QC1; (c) 54511 and (d) 54406 profiler station after IRMCD-based outlier detection in QC2 ( $\left.\mathrm{m} \mathrm{s}^{-1}\right)$.

background. Typical correlations between the observations and background are shown in Figs. 3a and 3b, demonstrating that at least one component of horizontal wind (eastward/northward velocity, referred to as $u / v$ ) does not meet the predefined threshold of 0.6 , which challenges the reliability of the profiler station.

The passing rate of QC2 only ranges from approximately $60 \%$ to $80 \%$, indicating that the profilers that have successfully passed QC1 still contain outliers. As shown in Figs. 3c and 3d, even for a profiler with a good match between the observations and the background (the correlation coefficients in regard to $u / v$ are $0.856 / 0.785$ and $0.797 / 0.845$, respectively), a few outliers below 2 $\mathrm{km}$ are identified in both components (Fig. 3a). Moreover, as the IRMCD approach is applicable to multidimensional data, certain points (between 5 and $6 \mathrm{~km}$ ) are also denoted as outliers only because one component of $u / v$ exhibits large discrepancies from its model background counterpart (Fig. 3b).
After the abovementioned blacklisting and outlier QC steps, the distributions of the observation-minus-background (OMB) for both $u / v$ components are more Gaussian-like (figures are not shown). Additionally, the skewness $C_{\text {sk }}$ and excess kurtosis $C_{\mathrm{ku}}$ coefficients that quantitatively describe the statistical distribution of the OMB values still indicate slightly negative biases (skewness values of -0.05 and -0.07 for $u / v$ ) that approach 0 , which suggests that the quality of the wind profiler data is almost ideal for performing further DA.

\section{b. Vertical thinning}

From the bottom to the high level of the troposphere, most deployed wind profilers operate under three observation modes, which correspond to vertical resolutions of 60,120 , and $240 \mathrm{~m}$. Therefore, a vertical thinning procedure is applied to the 

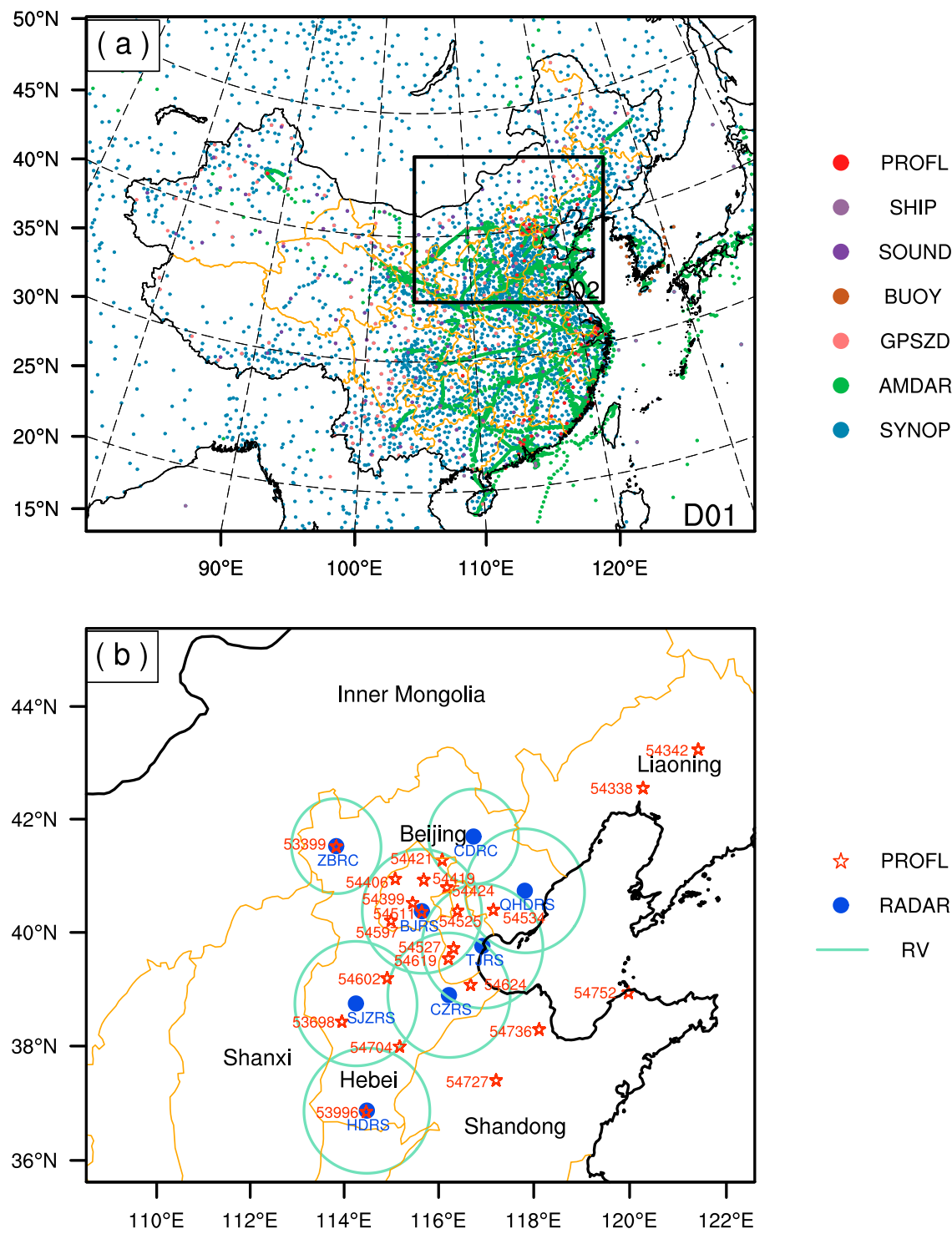

FIG. 4. (a) Domains and observations used in all the numerical experiments; (b) observation distributions in domain 2: profiler (red pentagrams) and Doppler radar (blue dots), maximum range coverage circles for radial velocity (solid green lines; $\mathrm{C}$ band: $115 \mathrm{~km}, \mathrm{~S}$ band: $150 \mathrm{~km}$ ).

QC-ed profiler data to alleviate the negative impacts due to the vertical correlation occurring in high-density observations. In this study, only the observations vertically closest to the height of each model level are retained for the subsequent DA, by which the profiler data to be assimilated are considered to have a vertical resolution that is comparable to that of the model.

\section{Rapid Refresh multiscale analysis and prediction system: Short-term and experimental design}

\section{a. Model and DA configurations}

All experiments performed in this study adopt the RMAPS-ST (Chen et al. 2009). The RMAPS-ST is a rapidly updated NWP system that was developed at the Institute of Urban Meteorology of the China Meteorological Administration (IUM/CMA), which provides short-term operational forecasts over mesoscale limited-area domains (horizontal resolution of $9 \mathrm{~km}$ ) covering the Chinese territory and a oneway nested $3-\mathrm{km}$ domain centered in the northern part of China (Fig. 4a). Its model and DA components are based on the Advanced Weather Research and Forecasting Model (WRF-ARW, version 3.8.1; Skamarock et al. 2008) and WRF DA model (WRFDA version 3.8.1; Barker et al. 2012), respectively.

In the RMAPS-ST system, multisource data, including conventional observations (Fig. 4a) collected by the Global Telecommunications System (GTS), surface observations 
TABLE 1. Experiment configurations.

\begin{tabular}{|c|c|c|c|c|}
\hline \multirow[b]{2}{*}{ Expt ID } & \multicolumn{4}{|c|}{ Assimilation strategy } \\
\hline & Pass & Data type & Len_scaling & VAR_scaling \\
\hline PROF & - & Profiler only & 1.0 & 1.0 \\
\hline RADV & - & Radial velocity only & $0.5(u, v)$ & $0.5(u, v)$ \\
\hline \multirow[t]{2}{*}{ CTRL } & Pass I & GTS & 1.0 & 1.0 \\
\hline & Pass II & Radial velocity + reflectivity & $0.5\left(u, v, t, p_{s}, q^{\prime}\right) ; 0.7\left(q_{r}\right)$ & $0.5\left(u, v, t, p_{s}, q^{\prime}\right)$ \\
\hline \multirow[t]{2}{*}{ PROF_PASS1 } & Pass I & GTS + profiler & 1.0 & 1.0 \\
\hline & Pass II & Radial velocity + reflectivity & $0.5\left(u, v, t, p_{s}, q^{\prime}\right) ; 0.7\left(q_{r}\right)$ & $0.5\left(u, v, t, p_{s}, q^{\prime}\right)$ \\
\hline \multirow[t]{2}{*}{ PROF_PASS2 } & Pass I & GTS & 1.0 & 1.0 \\
\hline & Pass II & Radial velocity + reflectivity + pProfiler & $0.5\left(u, v, t, p_{s}, q^{\prime}\right) ; 0.7\left(q_{r}\right)$ & $0.5\left(u, v, t, p_{s}, q^{\prime}\right)$ \\
\hline
\end{tabular}

retrieved from local automatic weather station (AWS) networks, and super-observations of the radial velocity and reflectivity acquired from the eight Doppler radars deployed in North China, are assimilated.

In the nested 3-km domain (D02), similar to Tong et al. (2016) and Xie et al. (2011), two analysis passes are sequentially implemented to assimilate different types of observations. Large-scale observations are assimilated first, followed by a second pass with a decreased correlation length to assimilate high-resolution observations, such as radar data. The GTS data, including sounding, radiosonde, AIREP, and BOUY data, are analyzed in the first pass (Pass I) with regular calculated length and variance scales (Len_scalings and Var_scalings) based on their coarse distribution, which are usually regarded as representing synoptic scales. In the second pass (Pass II), the analysis conducted in Pass I provides a first guess against which the radial velocity and reflectivity data retrieved from the eight Doppler radars deployed in the Beijing-Tianjin-Hebei region are assimilated at variance/length scales reduced by factors of 0.5 and 0.7 , respectively. For example, Len_scaling is set to 0.5 , which means that the default length scale of correlation distances is reduced by $50 \%$. Table 1 summarizes the assimilation parameters. The three-dimensional variational (3D-Var) option in the WRFDA model is selected as the assimilation technique of the RMAPS-ST system. The Cartesian eastward and northward velocity component $(u / v)$ schemes are adopted as momentum control variables in the BE calculations and DA, respectively, which reveals the superiority of convectionallowing DA and prediction approaches over conventional streamfunction and velocity potential control variable $(\psi / \chi)$ schemes (Sun et al. 2016; Wang et al. 2020). The complete control variables of the $u / v$ scheme include the eastward velocity components $(u)$, northward velocity components $(v)$, temperature $(t)$, surface pressure $\left(p_{s}\right)$, pseudo-relative humidity $\left(q^{\prime}\right)$, and rainwater $\left(q_{r}\right)$.

The assimilated radar radial velocity and reflectivity data are super-observations with a resolution of $3 \mathrm{~km} \times 3 \mathrm{~km} \times$ $500 \mathrm{~m}$ acquired from nine elevation angles $\left(0.5^{\circ}, 1.5^{\circ}, 2.4^{\circ}\right.$, $3.4^{\circ}, 4.3^{\circ}, 6.0^{\circ}, 9.9^{\circ}, 14.6^{\circ}$, and $\left.19.5^{\circ}\right)$ of eight Doppler radars after the implementation of a series of QC thinning and averaging procedures (Chen et al. 2014). Considering that the beam broadening makes reliability of Doppler winds decrease with distance from the radar, following Montmerle and Faccani (2009), the observation error of the radial velocity $\sigma_{o}$ is linearly adjusted with the distance $d$ to the location of the radar antenna as $\sigma_{o}(d)=(4 d / 250)+1$. Accordingly, the observation errors range from 1 to $3.4 \mathrm{~m} \mathrm{~s}^{-1}$ and from 1 to $2.84 \mathrm{~m} \mathrm{~s}^{-1}$ for S-band radar and C-band radar, respectively.

The model physics configurations include the Yonsei University (YSU) planetary boundary layer (PBL) scheme (Hong et al. 2006), Thompson microphysics scheme (Thompson et al. 2008), Rapid Radiative Transfer Model for General Circulation Models (GCMs) (RRTMG) schemes (Iacono et al. 2008) for both longwave radiation and shortwave radiation, unified Noah land surface model (Chen and Dudhia 2001), and Kain-Fritsch cumulus parameterization (Kain 2004) applied to the $9-\mathrm{km}$ domain. In the $3-\mathrm{km}$ domain, the

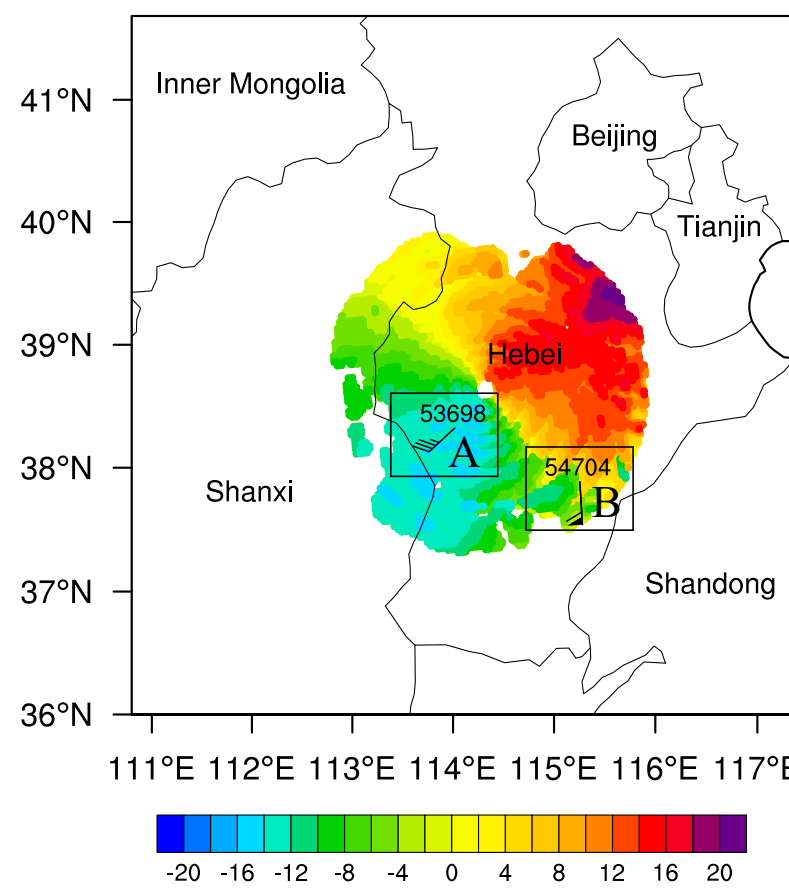

Fig. 5. The observed maximum radial velocity of Doppler radar super-observation (shaded; $\mathrm{m} \mathrm{s}^{-1}$ ) and profiler winds (black wind barbs; half barb $=2 \mathrm{~m} \mathrm{~s}^{-1}$, barb $=4 \mathrm{~m} \mathrm{~s}^{-1}$, flag $=20 \mathrm{~m} \mathrm{~s}^{-1}$ ) at $3.5-6.5 \mathrm{~km}$ at $0000 \mathrm{UTC} 17 \mathrm{Jul} 2018$. 
TABLE 2. Radial velocity/profiler wind speeds $\left(\mathrm{m} \mathrm{s}^{-1}\right)$ from the single- and dual-points experiments. The values in boldface represent radial velocity.

\begin{tabular}{|c|c|c|c|c|c|c|c|}
\hline \multirow[b]{2}{*}{ Scenario } & \multirow[b]{2}{*}{ Observation } & \multirow[b]{2}{*}{ Background } & \multicolumn{4}{|c|}{ Final analysis } & \multirow[b]{2}{*}{ Location } \\
\hline & & & RADV & PROF & PROF_PASS1 & PROF_PASS2 & \\
\hline I & $-\mathbf{1 3 . 4 5 9} / 13.2$ & $-\mathbf{1 1 . 0 5 5} / 12.247$ & $-\mathbf{1 3 . 1 7 3} / 14.178$ & $-\mathbf{1 1 . 4 4 5 / 1 2 . 6 5 7}$ & $-\mathbf{1 3 . 2 2} / 14.272$ & $-\mathbf{1 2 . 8 4 6} / 13.986$ & $38.00^{\circ} \mathrm{N}, 114.38^{\circ} \mathrm{E}, 5333.9 \mathrm{~m}$ \\
\hline II & $-\mathbf{5 . 7 9 5} / 23.8$ & $-\mathbf{9 . 3 5 9} / 18.048$ & $-6.779 / 16.763$ & $-\mathbf{1 1 . 7 5 / 2 0 . 6 9 4}$ & $-\mathbf{7 . 4 4} / 18.434$ & $-\mathbf{1 0 . 5 2 8} / 20.876$ & $37.52^{\circ} \mathrm{N}, 115.62^{\circ} \mathrm{E} ; 4201.9 \mathrm{~m}$ \\
\hline
\end{tabular}

Kain-Fritsch cumulus parameterization is deactivated while other physics configurations are the same as those in 9-km domain.

The RMAPS-ST system relies on a forward 3-h intermittent assimilation cycle. A partial cycling technique is applied by initiating the model at 1800 UTC, which is directly driven by the $0.125^{\circ} \times 0.125^{\circ}$ European Centre for Medium-Range Weather Forecasts (ECMWF) global forecast (cold start), is integrated over $6 \mathrm{~h}$ to generate valid forecasts at $0000 \mathrm{UTC}$ and serves as the first guess for DA purposes. We then follow the 3-h updated intermittent assimilation and forecast cycles with the latest observations collected from various data sources within the \pm 1.5 -h time window assimilated against the 3 -h forecast obtained in the previous cycle. The forecast length is $24 \mathrm{~h}$ in each cycle.
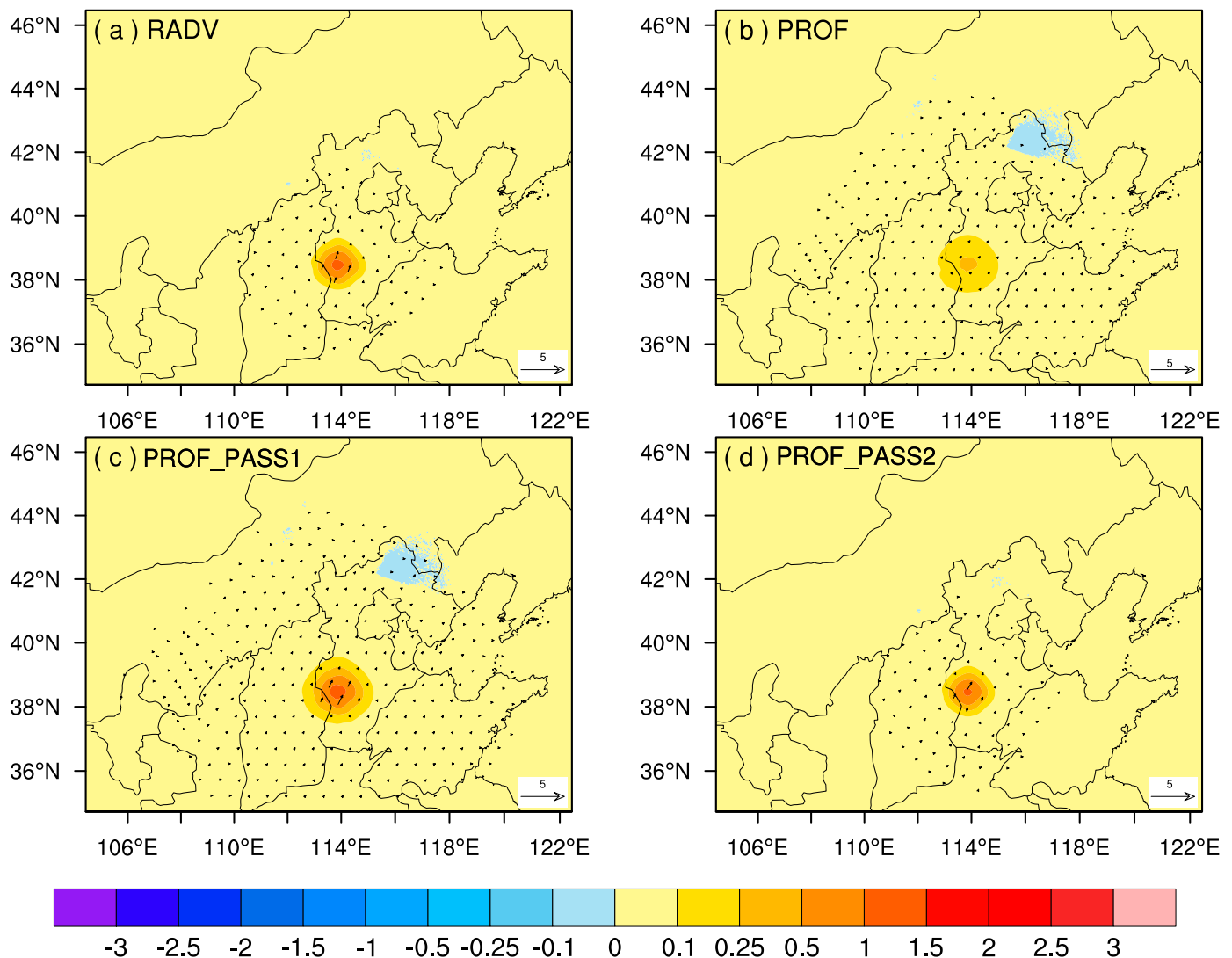

FIG. 6. Analysis increments of horizontal wind speeds $\left(\mathrm{m} \mathrm{s}^{-1}\right)$ and vectors for single and dual-observation tests at a model level of 19: (a) RADV, (b) PROF, (c) PROF_PASS1, and (d) PROF_PASS2 experiments.

\section{b. Experimental design}

Figure $4 \mathrm{~b}$ displays the distribution of the wind profiler stations and maximum coverage of the radial velocity observations retrieved from the radar network in the BeijingTianjin-Hebei region. Seven wind profilers are deployed within the radial velocity coverage area of the BJRS radar, which is the only Doppler radar that provides volume scans of the entire Beijing area. To consider the relative importance and contributions of both wind observations in convectivescale DA, three experiments denoted as CTRL, PROF PASS1 and PROF_PASS2 are conducted (as summarized in Table 1), which differ based on the assimilation strategy that is implemented in regard to the profiler data and Doppler radar radial velocity. The benchmark experiment is denoted as CTRL, a regular 3-h update cycling with the assimilation of

\section{.}



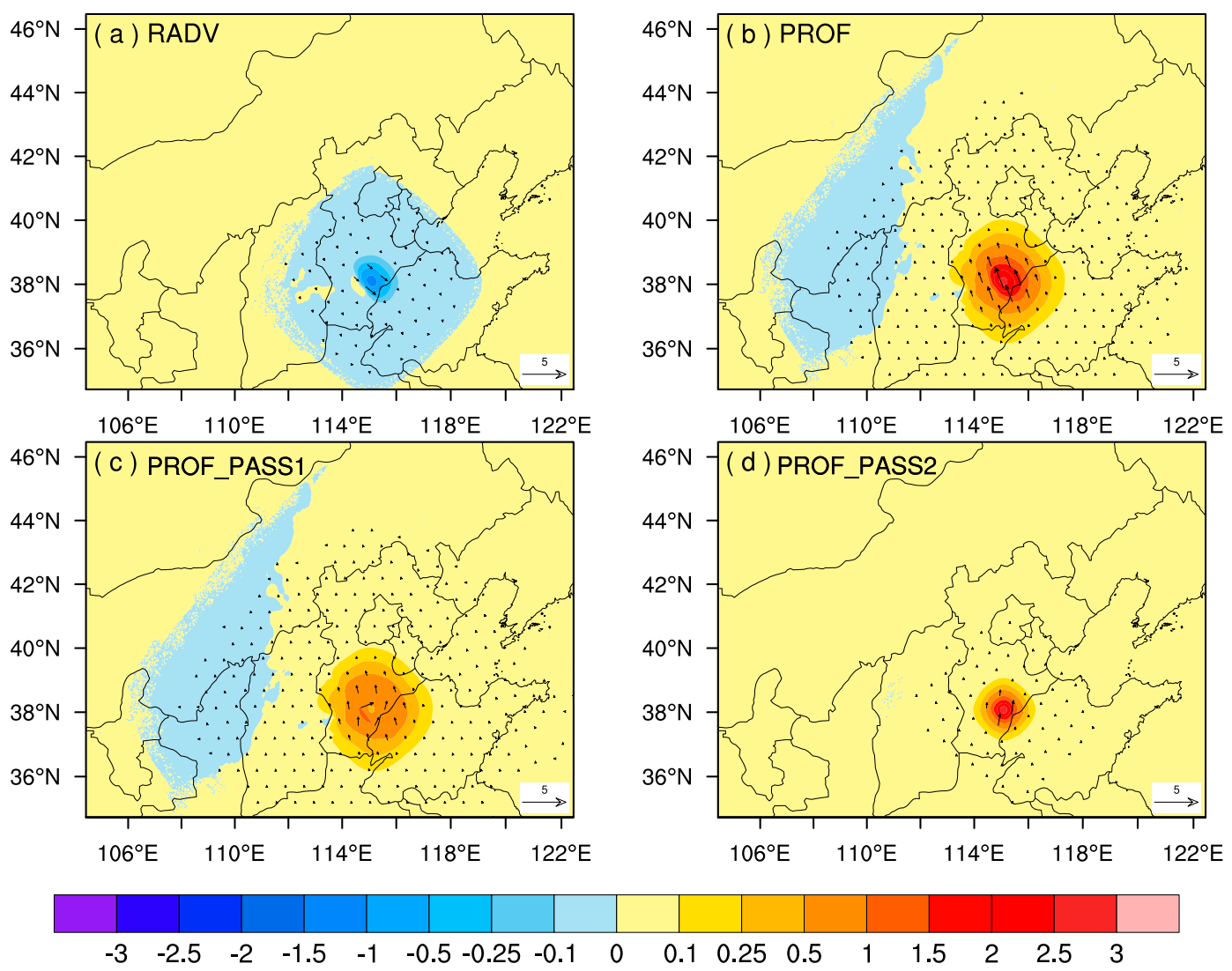

FIG. 7. As in Fig. 6, but for the scenario II (54704).

Doppler radar data using the two-pass strategy. In the PROF_PASS1 and PROF_PASS2 experiments, the profiler data are assimilated in the first pass and second pass with regular and tuned background correlation scalings, respectively. As indicated in Table 1, the PROF and RADV experiments are two single-observation tests to compare the relative impacts of the assimilation of either profiler data or radial velocity data.

\section{Results}

\section{a. Single- and dual-observation tests}

A single-observation test is usually performed to identify the range of the observed information via established correlations among 3D-VAR control variables (Xiao and Sun 2007). To explore the wind analysis increments in response to the different observations and assimilation strategies, a series of single-observation tests are performed by assimilating profiler and Doppler radar radial velocity observations at the same location. Additionally, dual-observation tests are performed by involving the individual and combined assimilation of pairs of true radial velocities and profiler observations. Because the radial wind direction is a function of location with respect to the radar and not a function of wind direction, for simplicity, two typical scenarios are considered. These scenarios represent the two "extreme" situations in which the radial wind direction is relative to the prevailing wind to reveal whether the radial velocity acquired from a single radar fully reflects the wind vectors measured by a profiler. In scenario I, the direction of environmental wind represented by profiler observations is approximately consistent with the radial wind direction. Scenario II describes the situation in which the profiler observation-revealed wind direction largely deviates from or is nearly orthogonal to the radial wind direction. Although both radial velocity and profiler independently observe atmospheric motion from different perspectives, profiler observations are considered to reveal the ground truth as they are direct observations of wind vectors.

Experimental information is provided in Table 1. In each scenario, the locations of the pairs of profiler and radial velocity observations within the same grid box and at similar heights are shown in Fig. 5. Detailed information about the experiments is listed in Table 2. The background field is the 12-h ECMWF forecast at 0000 UTC 17 July 2018. Figures 6 and 7 show the horizontal wind speed and vector analysis increments for all experiments in the abovementioned two scenarios. It should be noted that the analysis increments are the differences between the final analysis and the first guess, regardless of whether a single-analysis pass or two analysis pass experiments are performed. 
(a) OBS

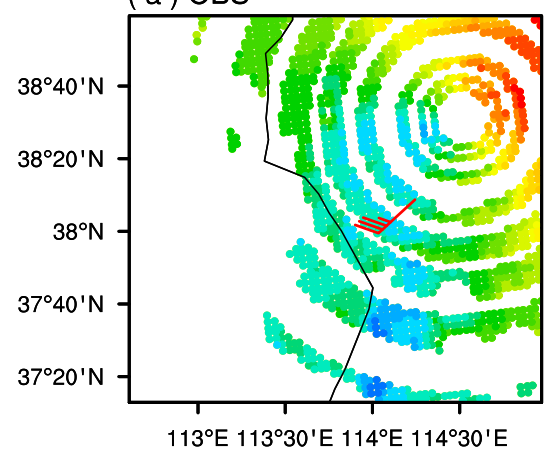

(d) PROF

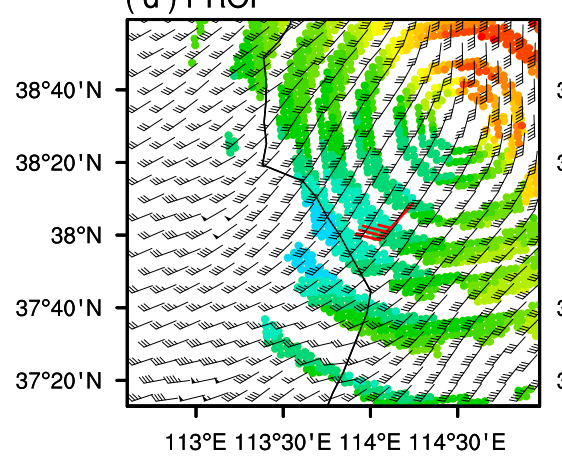

(b) FG

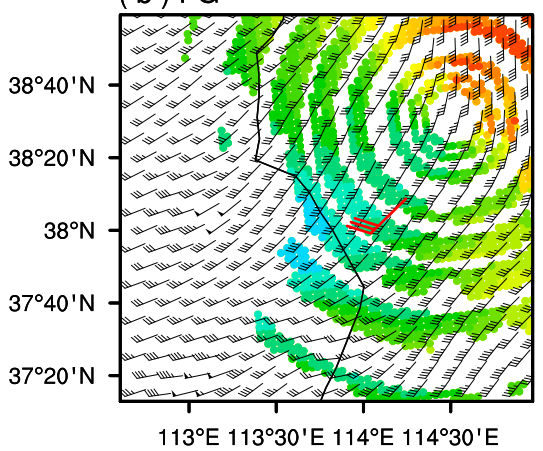

(e) PROF_PASS1

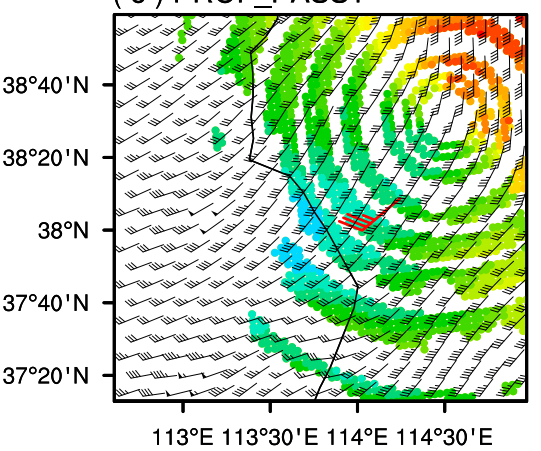

(c) RADV

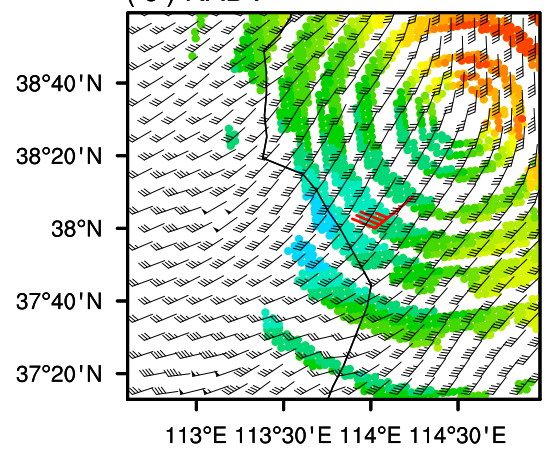

( $f$ ) PROF_PASS2

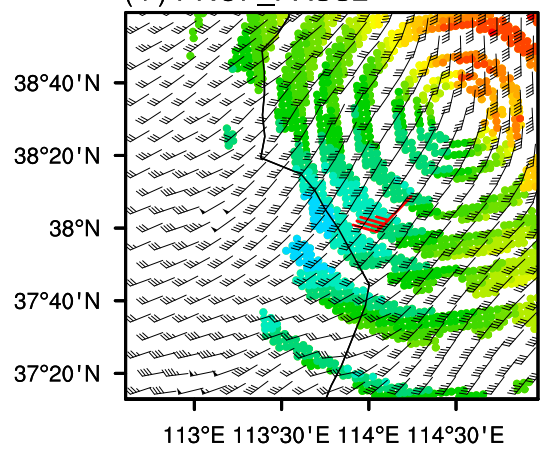

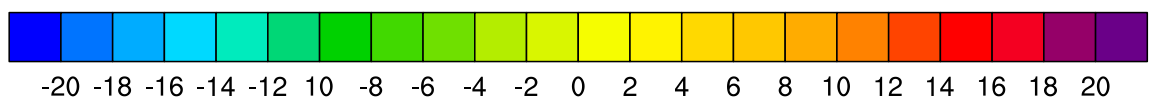

FIG. 8. Radial velocity (shaded; $\mathrm{m} \mathrm{s}^{-1}$ ) at $5-6 \mathrm{~km}$, profiler winds (red wind barbs), and horizontal wind vectors (black wind barbs) for the scenario I (53698): (a) OBS, (b) FG, (c)RADV, (d) PROF, (e) PROF_PASS1, and (f) PROF_PASS2 experiments; wind barbs (half barb $=2 \mathrm{~m} \mathrm{~s}^{-1}$, barb $=4 \mathrm{~m} \mathrm{~s}^{-1}$, flag $\left.=20 \mathrm{~m} \mathrm{~s}^{-1}\right)$.

Within the coverage area of a single radar, i.e., SJZRS (located in Shijiazhuang City, Hebei Province), in scenario I, the radial direction at point $\mathrm{A}$ is generally consistent with the horizontal wind observed by profiler 53698. Correspondingly, the radial velocity $\left(-13.459 \mathrm{~m} \mathrm{~s}^{-1}\right)$ approaches the observed wind speed $\left(13.2 \mathrm{~m} \mathrm{~s}^{-1}\right)$. Notably, whether the profiler wind is assimilated in Pass I or Pass II, the wind analysis increments exhibit similar patterns and magnitudes (Fig. 6). Based on Table 2, to a certain extent, the final analyzed wind speeds in all tests at this point approach the observations, and no large differences are identified between the final analyzed wind fields and the radial velocities, as shown in Fig. 8.

In scenario II, at point $\mathrm{B}$, the analyzed results in all experiments are shown in greater detail in Fig. 9 and Table 2. The wind speed $\left(23.8 \mathrm{~m} \mathrm{~s}^{-1}\right)$ observed by profiler 54704 reveals the occurrence of a strong southerly jet (Fig. 9a). However, the radial velocity at this point is observed to be $-5.795 \mathrm{~m} \mathrm{~s}^{-1}$; thus, at this point, there is only a small fraction of the actual wind decomposed along the radial direction. With profiler observations assimilated independently, the wind analysis of the PROF experiment is improved from $18.048 \mathrm{~m} \mathrm{~s}^{-1} / 190.7^{\circ}$ (background, as shown in Fig. 9b) to $20.694 \mathrm{~m} \mathrm{~s}^{-1} / 187.2^{\circ}$ (Fig. 9d), approaching $23.8 \mathrm{~m} \mathrm{~s}^{-1} / 184.0^{\circ}$. However, in the RADV test, the analyzed radial velocity is adjusted from $-9.359 \mathrm{~m} \mathrm{~s}^{-1}$ (background) to $-6.779 \mathrm{~m} \mathrm{~s}^{-1}$ (analysis), which nears the ground truth $\left(-5.795 \mathrm{~m} \mathrm{~s}^{-1}\right)$ and corresponds to a reduction in the wind speed/direction from $18.048 \mathrm{~m} \mathrm{~s}^{-1} / 190.7^{\circ}$ (background) to $16.763 \mathrm{~m} \mathrm{~s}^{-1} / 197.8^{\circ}$ (analysis, as shown in Fig. 9c), indicating that the analyzed wind greatly deviates from the ground truth $\left(23.8 \mathrm{~m} \mathrm{~s}^{-1} / 184.0^{\circ}\right)$ when only radial velocity is assimilated. A similar situation occurs in the second pass in the PROF_PASS1 experiment. Serving as the first guess of this step, the analysis of the PROF experiment yields a radial velocity of $-11.75 \mathrm{~m} \mathrm{~s}^{-1}$ and a wind analysis of $20.694 \mathrm{~m} \mathrm{~s}^{-1} /$ $187.2^{\circ}$, which are quite close to the ground truth. With the radial velocity $\left(-5.795 \mathrm{~m} \mathrm{~s}^{-1}\right)$ assimilated in the second pass, the final analysis of the PROF_PASS1 experiment indicates a radial velocity of $-7.44 \mathrm{~m} \mathrm{~s}^{-1}$, and the retrieved wind speed/ direction is degraded from $20.694 \mathrm{~m} \mathrm{~s}^{-1} / 187.2^{\circ}$ to $18.434 \mathrm{~m} \mathrm{~s}^{-1}$ / $197.7^{\circ}$ (Fig. 9e). We observe that the assimilation of only the radial velocity at this point degrades the analysis, i.e., the improvement obtained due to profiler DA is partly canceled by the negative impact of the radial velocity in the second pass.

In the PROF_PASS2 experiment, the final analysis obtained with the combined assimilation of weak radial wind and strong profiler observations is $20.876 \mathrm{~m} \mathrm{~s}^{-1} /$ $191.5^{\circ}$ (Fig. 9f), which best approaches the ground truth 


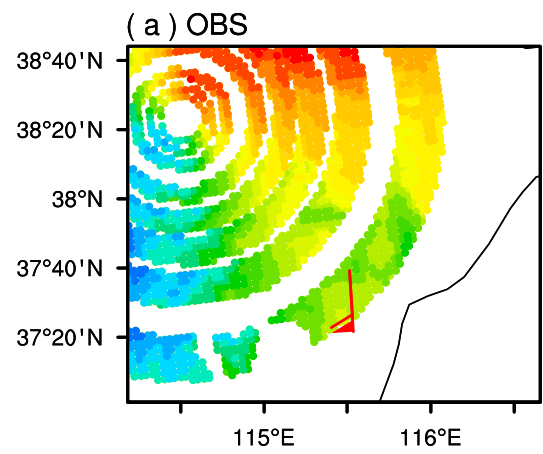

(d) PROF

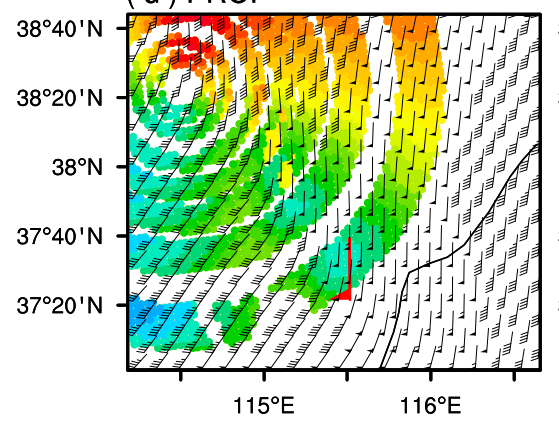

(b) FG

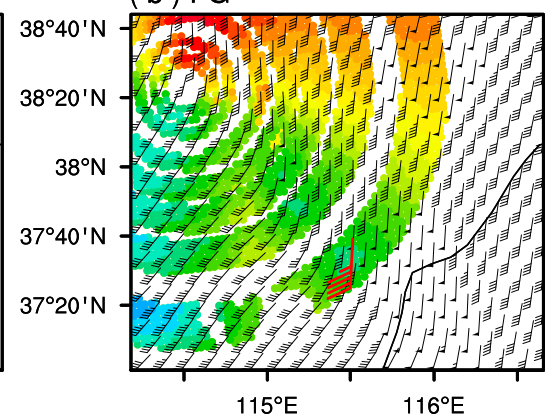

(e) PROF_PASS1

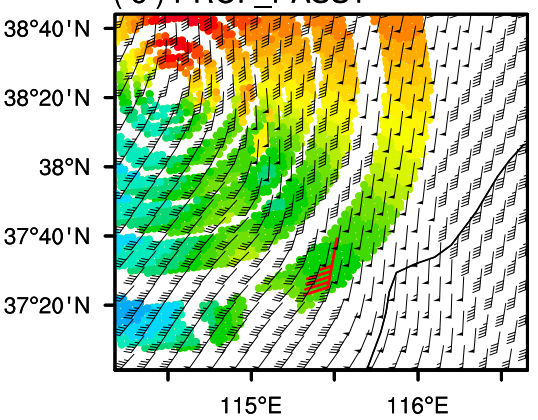

(c) RADV

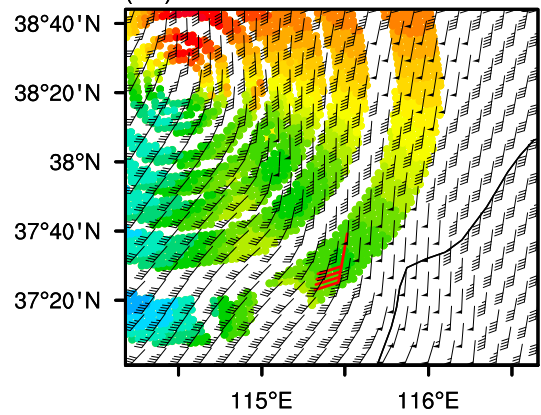

(f) PROF_PASS2

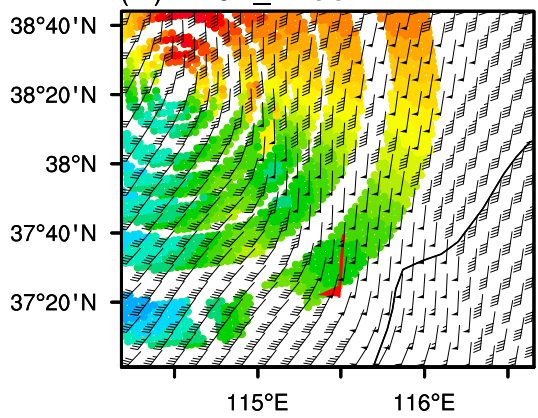

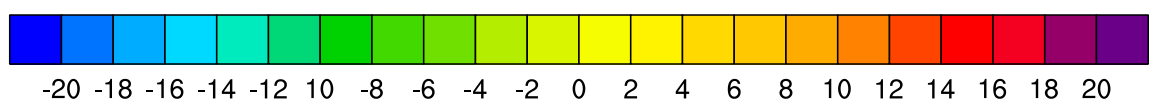

FIG. 9. As in Fig. 8, but for the scenario II (54704) and radial velocity at 4-5 km.

among the four experiments. The PROF_PASS2 experiment is the only strategy in which profiler DA provides notable complements to single-point test of radial velocity DA. Moreover, as shown in Fig. 7, the relatively large areas with wind speeds exceeding $20 \mathrm{~m} \mathrm{~s}^{-1}$ demonstrate that the analyzed wind fields approach the environmental jet speed when profiler data are assimilated.

As shown in Fig. 7, the RADV experiment generates weak northwest wind analysis increments, while the large increments generated in the PROF experiment cover nearly the entire domain area. The PROF_PASS1 experiment reproduces most of the horizontal and vertical structures (not shown) of the PROF experiment, especially the pattern and extent of the increments, while the distorted southwest incremental wind vectors among the southeast incremental wind vectors revealed slight influences by the assimilation of radial velocity at Pass II. The PROF_PASS2 experiment, in which the observations are both assimilated at a configuration scale reduced by a factor of 0.5 , yields analysis increments with a small influence range similar to those in the RADV experiment and notable analysis increment extremes approaching those in the PROF_PASS1 experiment from the assimilation of profiler data.

Based on these simple experiments, we conclude that the assimilation of radial wind data does not always generate positive effects. For radial velocity observations from a single radar, as they have fewer (only radial direction) dimensions than the property (2D or $3 \mathrm{D}$ wind) that they are observing, multiple observations from other radar(s) or wind measurements are required to provide enough information to resolve the wind. The assimilation of radial wind only adjusts the radial component of the wind field toward the observations, but the non-detectable tangential wind component originating from the first guess always remains untouched. When radial winds are the dominant components of both the background and the observations, as shown in scenario I, radial wind assimilation expectedly generates positive effects. Conversely, the actual effect of radar radial wind assimilation is uncertain and may even degrade analyses. Scenario II represents just one possible situation in which many local variations in radial velocities representing the concurrence of local convection (Fig. 5). In this case, the likelihood that the observed radial wind shows agreement with the model field is much lower, thus potentially compromising the analysis.

When only single-radar data are assimilated, any other wind observation information (such as that obtained from wind profilers or from other adjacent radars) could provide important complements via the constraint of the combined assimilation of both observations. Additionally, as shown in Figs. 6 and 7, the PROF and PROF_PASS1 experiments generate relatively wider spread increments as the profiler observations are assimilated at a regular scale, while the RADV 
and PROF_PASS2 experiments rely on configuration scales reduced by a factor of 0.5 . However, the assimilation of two very different types of independent observations is much more complicated. When both assimilated observations originate from dense local networks, it is more reasonable to restrict the impacts of each observation type within a limited area, as seen in the PROF_PASS2 experiment.

\section{b. Low-level jet case study}

\section{1) CASE OVerview}

From 16 to 18 July 2018, a series of convective storms accompanied by a strong LLJ produced persistent heavy rainfall and a nearly 8-yr, maximum accumulated precipitation in the Beijing area. From 1200 UTC 15 July to 1200 UTC 17 July, the AWS, station-average and accumulated rainfall reached approximately $103.1 \mathrm{~mm}$, while at more than 16 stations in the Beijing area, the observed accumulated rainfall exceeded $200 \mathrm{~mm}$.

In this case, a strong LLJ to the east of a deep low vortex was identified in the middle and lower troposphere with wind speeds greater than $12 \mathrm{~m} \mathrm{~s}^{-1}$ (Fig. 10a) and even exceeding $20 \mathrm{~m} \mathrm{~s}^{-1}$ in the Beijing area at 0000 UTC 17 July 2018. Its structure was captured in detail by the local profiler network during the event (Fig. 11). Based on the 3-day time series of the profiler observations (Fig. 11), profilers 54597 (Fig. 11a) and 54406 (Fig. 11b) are located along the northwest edge of the LLJ. Their observed southerly jet core was mainly located below $4 \mathrm{~km}$ and lasted for only $3 \mathrm{~h}$ from 0300 to 0600 UTC 17 July 2018. However, the direction of the LLJ detected by profilers 54511 (Fig. 11g) and 54419 (Fig. 11h) switched from a southerly direction to a southwesterly direction, thereby prevailing for a much longer time, and the observed depth even reached a height of $8 \mathrm{~km}$. Correspondingly, as shown in Fig. 10b, the LLJ was also identified based on the radial velocity data recorded by Doppler radar BJRS, which is the only radar covering the entire Beijing area. Therefore, this event is selected as a specific case to study the combined impacts of the combined assimilation of profiler data and radial velocity.

\section{2) ANALYSIS AND FORECAST EVALUATION OF WINDS}

For each profiler, the analyzed and subsequent 1-3-h forecasted wind profiles initiating at two selected times, which are considered typical moments of the LLJ, are shown in Fig. 11. When the profiler data were decomposed according to the position of the profiler relative to the antenna of the BJRS radar, large variations were observed, implying that the impacts of profiler assimilation differed from station to station.

The situation for profiler 54419 is quite similar to that of scenario I. As the profiler station is located north of the BJRS radar, the directions of its observed prevailing strong southwesterly below $5 \mathrm{~km}$ were quite consistent with those of the radial winds. The CTRL experiment captured the LLJ with the assimilation of radial velocity data only. Large increments were also observed in the analysis at 0600 UTC (Fig. 13) compared with the first guess provided by the 3 -h forecast of the previous cycle.

The strong southerlies detected by profilers 54597 and 54406 in the low troposphere exhibited large angles with their
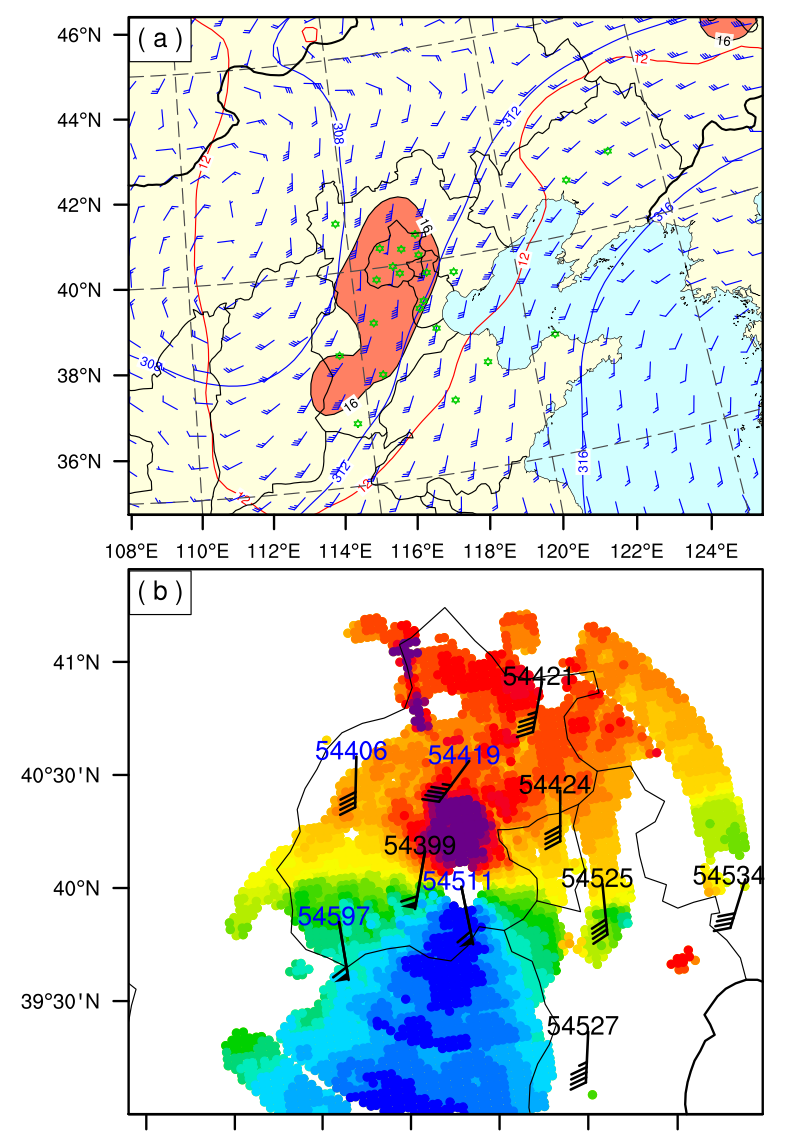

$114^{\circ} 30^{\prime} \mathrm{E} 115^{\circ} \mathrm{E} 115^{\circ} 30^{\prime} \mathrm{E} 116^{\circ} \mathrm{E} 116^{\circ} 30^{\prime} \mathrm{E} 117^{\circ} \mathrm{E} 117^{\circ} 30^{\prime} \mathrm{E}$

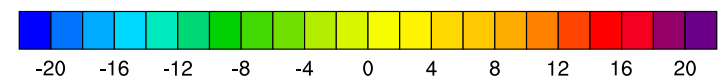

FIG. 10. (a) Horizontal wind vectors ( $\mathrm{m} \mathrm{s}^{-1}$; blue wind barbs), geopotential heights (gpm; solid blue lines; contour interval of $4 \mathrm{gpm})$, temperature $\left({ }^{\circ} \mathrm{C}\right.$; solid red lines; contour interval of $4^{\circ} \mathrm{C}$ ), wind speeds over $12 \mathrm{~m} \mathrm{~s}^{-1}$ (red shading) at $850 \mathrm{hPa}$ and profiler station locations (green hexagons) at 0000 UTC 17 Jul 2018. (b) The observed maximum radial velocity $\left(\mathrm{m} \mathrm{s}^{-1}\right)$ from BJRS Doppler radar super-observation and profiler winds (black wind barbs; half barb $=2 \mathrm{~m} \mathrm{~s}^{-1}$, barb $=4 \mathrm{~m} \mathrm{~s}^{-1}$, flag $=20 \mathrm{~m} \mathrm{~s}^{-1}$ ) at 2-4 $\mathrm{km}$ at 0000 UTC 17 Jul 2018.

radial directions, which suitably correspond to scenario II. The site of profiler 54511 overlaps BJRS, and few radial velocity records can be acquired above the radar antenna. With only radial wind assimilated, it was found that the LLJ was generally underestimated in the CTRL experiment by the three profilers. Nevertheless, the analysis results of both the PROF_PASS2 experiment and the PROF_PASS1 experiment were more consistent with the profiler observations, and in particular, the vertical structures of the horizontal winds were much better captured by the PROF_PASS2 experiment. Although less frequent and sparser in altitude than profilers, pilots collected at 54511 provide an independent observation data source to quantitatively evaluate the quality of wind analysis. The observed and analyzed pilot data from 

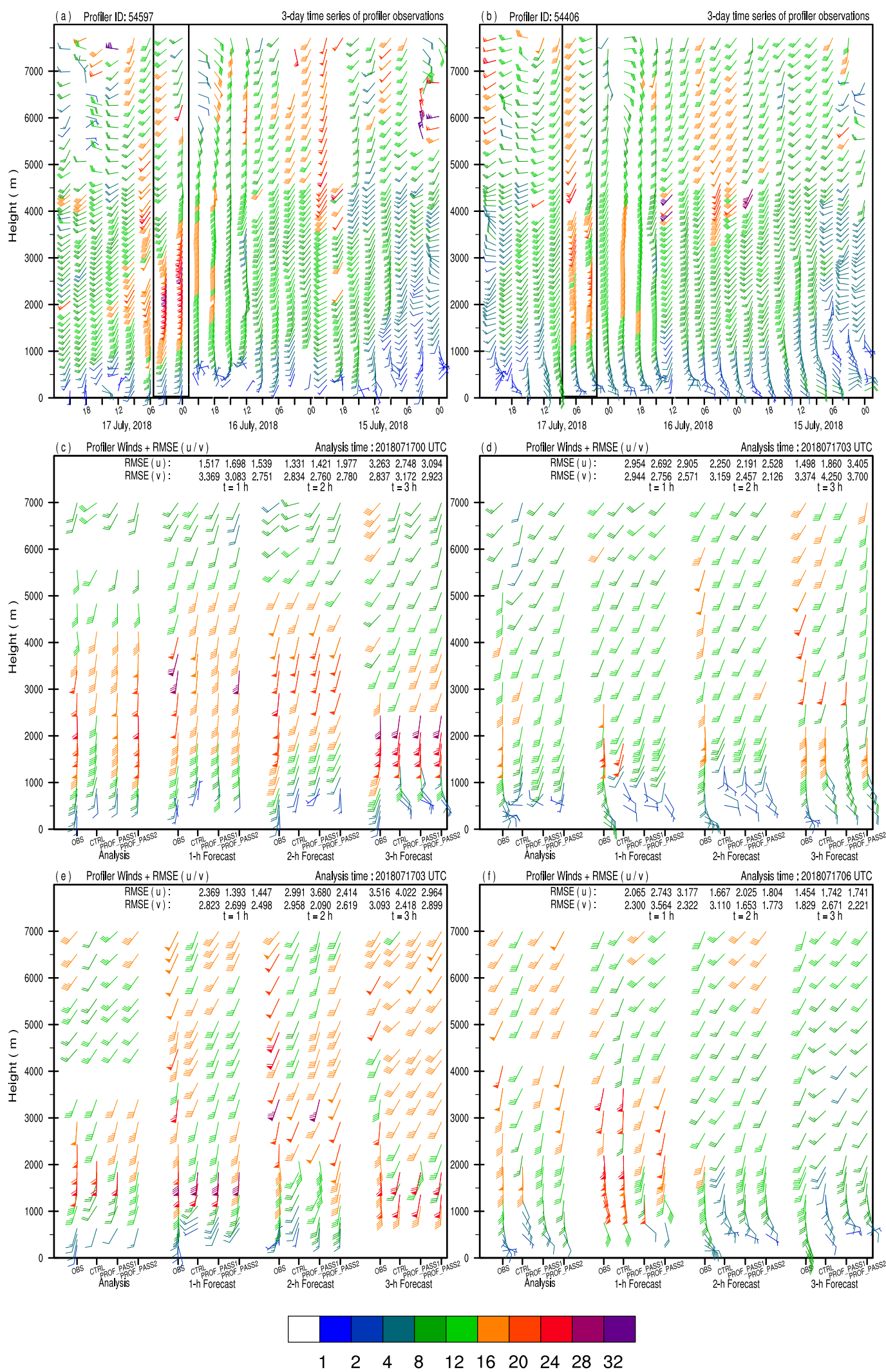

FIG. 11. The observed wind profile time series during the periods from 0000 UTC 15 Jul to 2100 UTC 17 Jul 2018. The analysis and corresponding $t=1-3$-h forecasted wind profiles initiating from two typical selected time from (a)-(c) 54419, (d)-(f) 54406, (g)-(i) 54597, and (j)-(l) 54511 (half barb $=2 \mathrm{~m} \mathrm{~s}^{-1}$, barb $=4 \mathrm{~m} \mathrm{~s}^{-1}$, flag $=20 \mathrm{~m} \mathrm{~s}^{-1}$ ). 

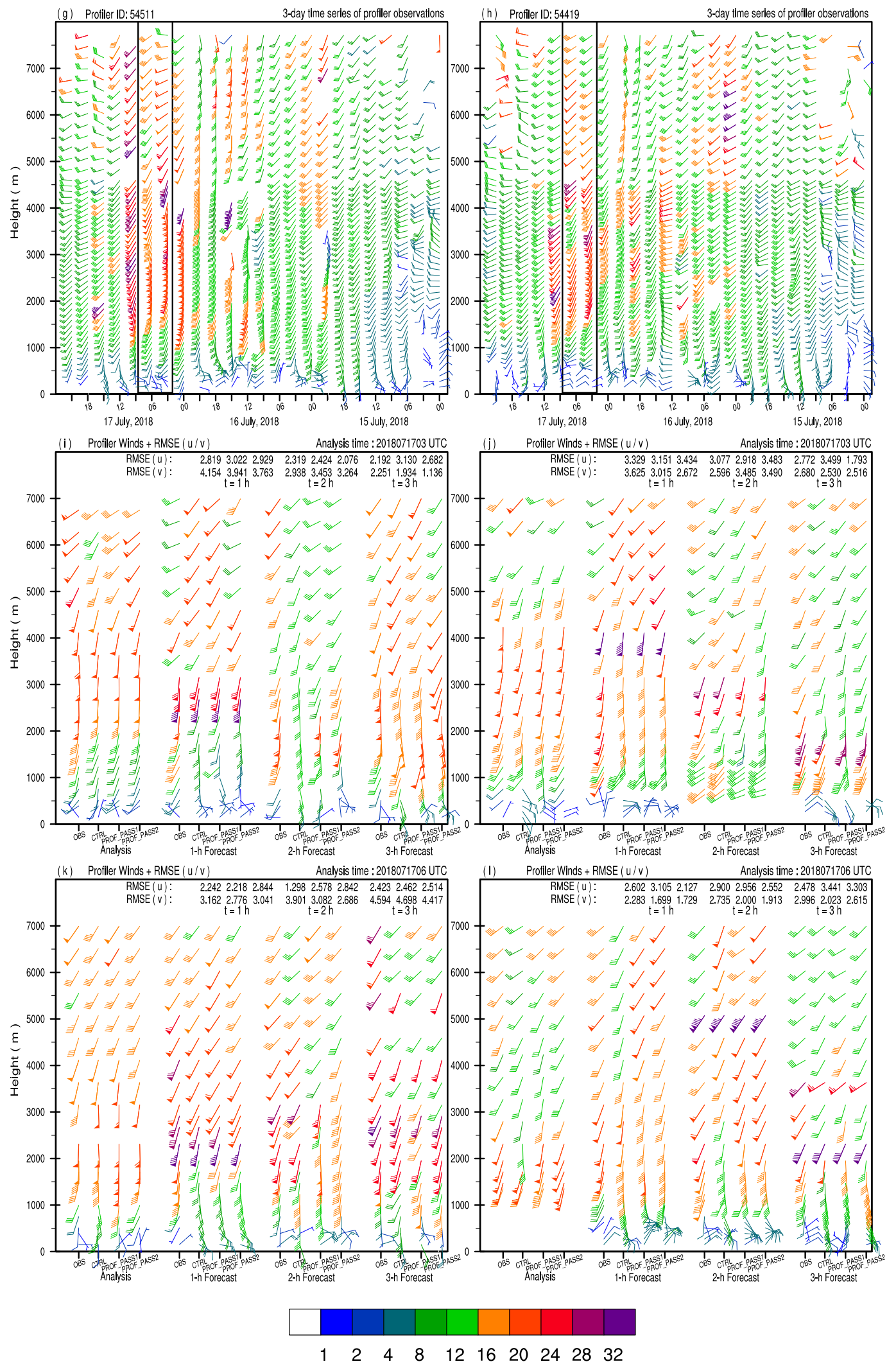

FIG. 11. (Continued). 

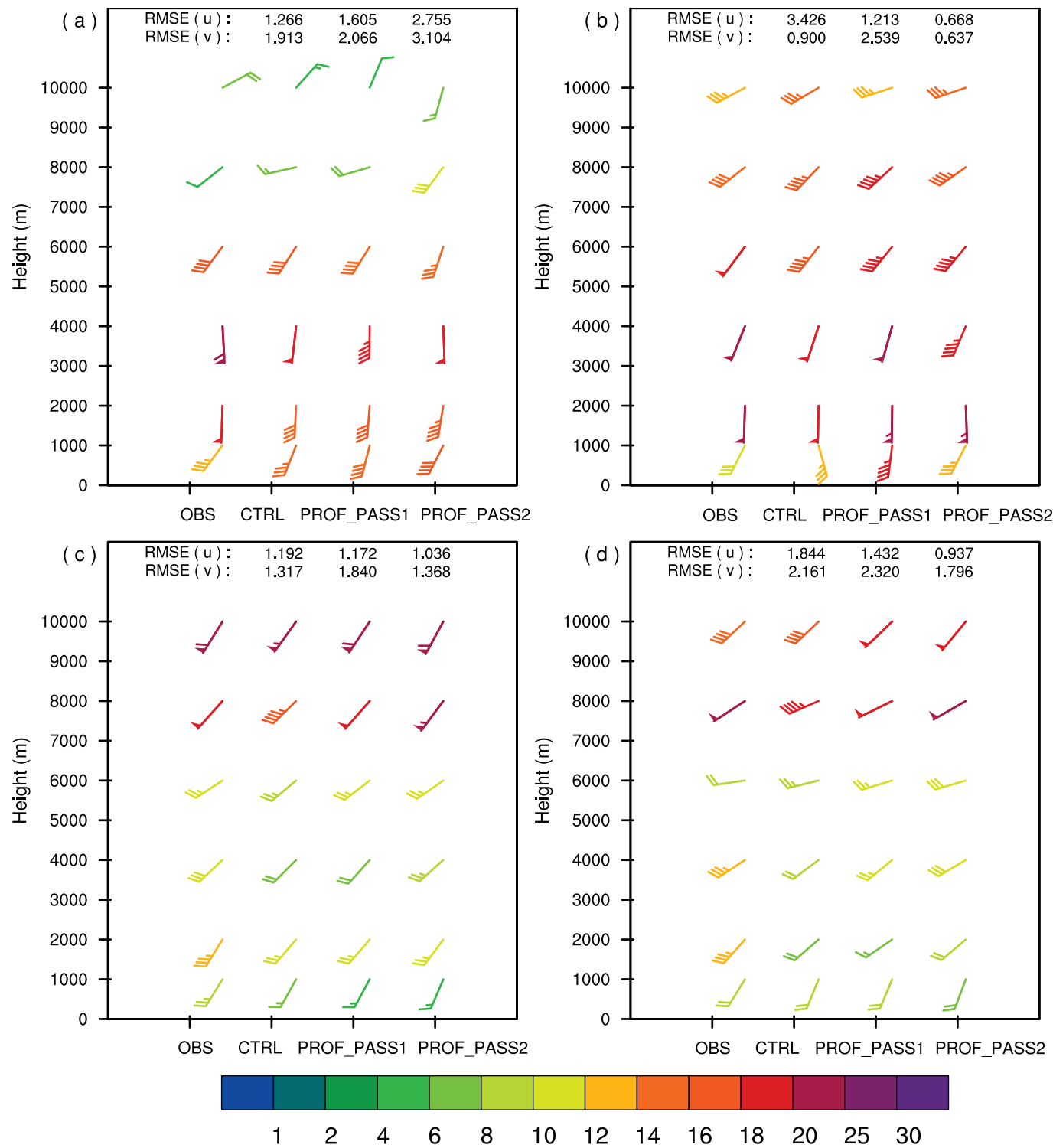

FIG. 12. The observed pilot observations from 54511 and analysis of wind at periods at $0000,0600,1200$, and 1800 UTC $117 \mathrm{Jul} 2018$ (half barb $=2 \mathrm{~m} \mathrm{~s}^{-1}$, barb $=4 \mathrm{~m} \mathrm{~s}^{-1}$, flag $=20 \mathrm{~m} \mathrm{~s}^{-1}$ ).

54511 valid at 0000, 0600, 1200, and 1800 UTC 17 July 2018 are shown in Fig. 12. Generally, without the assimilation of wind profiler data, the CTRL experiment underestimated the analyzed horizontal wind speeds in the lower troposphere, whereas the PROF_PASS1 and PROF_PASS2 experiments yielded larger horizontal wind speeds at 0600, 1200, and 1800 UTC, which are more similar to the pilot observations. In addition, the root-mean-square error (RMSE) of the three experiments calculated against the pilots confirmed that both the PROF_PASS1 experiment and PROF_PASS2 experiment have a better analysis quality than CTRL; in particular, the PROF_PASS2 experiment yields the best fit of the observations most of the time.

Only when the wind forecast is improved can we declare that profiler DA is beneficial. An improved wind analysis acquired from the assimilation of profiler data exerts small positive impacts on the consequent short-range forecasts (Fig. 11). In regard to all four profilers, the forecasted LLJs in the CTRL experiment are generally underpredicted over the observations and the PROF_PASS1 and PROF_PASS2 experiments. These results are also supported by the RMSE scores against the profiler observations, and the PROF PASS1 and PROF_PASS2 experiments usually attain lower forecasting RMSE than that of the CTRL experiment.

\section{3) ANALYSIS DIFFERENCES}

The differences in wind analysis from the CTRL experiment at 0000 UTC 17 July 2018 are compared to understand how the two profiler DA strategies modify the initial 

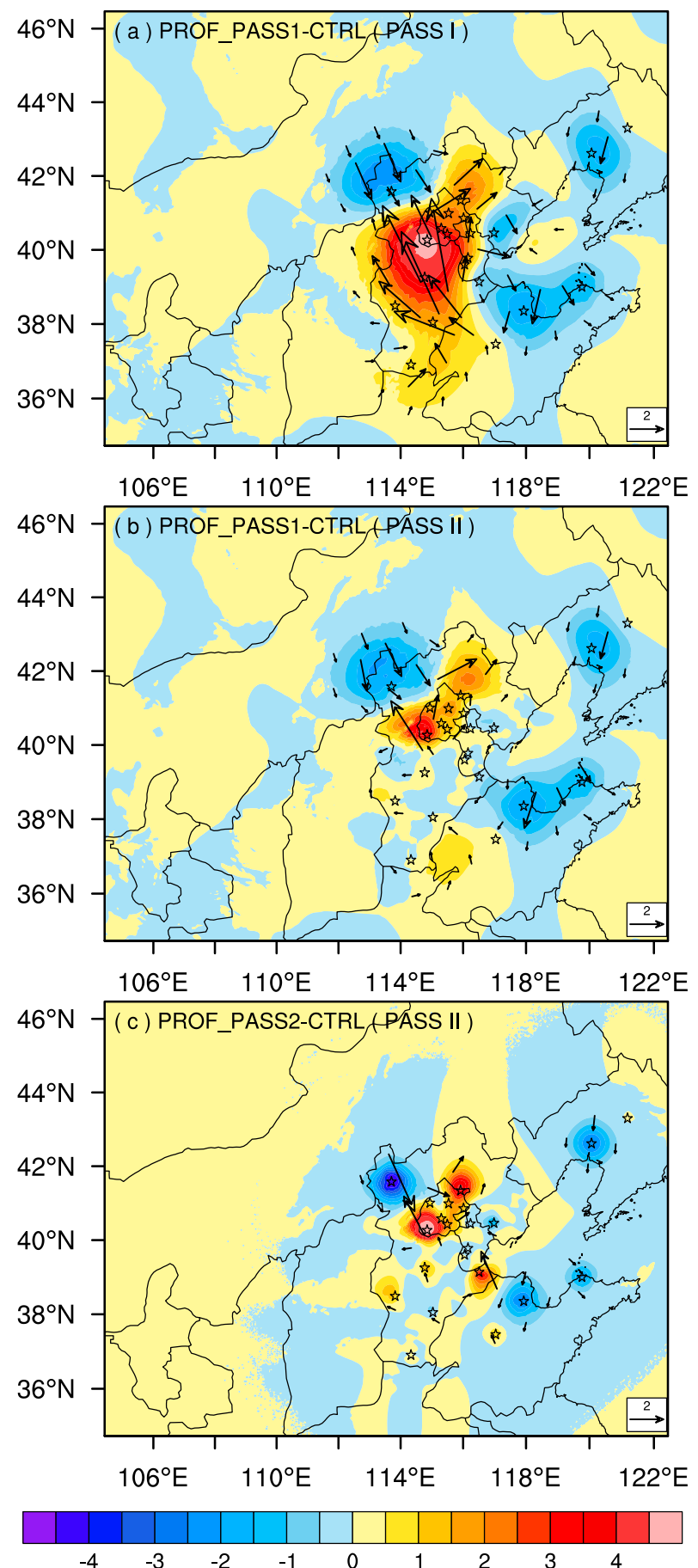

FIG. 13. The analysis differences of horizontal wind speeds initialized at 0000 UTC 17 Jul 2018 of model level 12: (a) PROF_PASS1-CTRL (PROF_PASS1 minus CTRL after Pass I), (b) PROF_PASS1-CTRL (PROF_PASS1 minus CTRL after Pass II), and (c) PROF_PASS2CTRL (PROF_PASS2 minus CTRL after Pass II) $\left(\mathrm{m} \mathrm{s}^{-1}\right)$.

conditions. As shown in Fig. 13a, a strong, widespread wind analysis difference is observed across the entire Hebei Province where the LLJ is located, which reveals the notable impact of the profiler DA strategy in Pass I of the
PROF_PASS1 experiment. Obviously, with the radial velocity assimilated in Pass II, whether the profilers are defined as synoptic-scale or storm-scale observations, both the PROF_ PASS1 experiment and PROF_PASS2 experiment yield similar wind analysis increment patterns compared to those of the CTRL experiment (Figs. 13b,c). Their final analysis increments are quite similar. The large increments generated as a first guess in Pass I of the PROF_PASS1 experiment in the LLJ area are largely suppressed when the Doppler radar radial velocity is assimilated. In the PROF_PASS2 experiment, the combined assimilation of profiler and radial velocity data generates moderate increments, indicating the mutual constraints of these two observation types.

In the PROF_PASS1 and PROF_PASS2 experiments, compared to the CTRL experiment, the two strengthened northwest and southeast wind increment centers indicate deceleration and acceleration, respectively, of the south wind components, causing an intensified convergence to the west of the Beijing area. It should be noted that their strengthened centers coincide with the two profiler stations 53399 and 54579 (Figs. 13b,c). Similar to the abovementioned single- and dual-observation tests, the PROF_PASS1 experiment produces a relatively large increment range, while the PROF_PASS2 experiment generates relatively notable (beyond $6 \mathrm{~m} \mathrm{~s}^{-1}$ ) but more localized wind analysis differences.

\section{4) Precipitation forecasts}

The observed and forecasted 3-h accumulated precipitation levels from the four cycles initialized at 0000, 0300, 0600, and 0900 UTC 17 July 2018 by the three experiments are shown in Fig. 14. For the two cycles initiating at 0000 and 0300 UTC, none of the experiments yield good precipitation forecasts in terms of location and intensity. The line-shaped rainband incorrectly forecasted by the CTRL experiment could not be mitigated with the assimilation of profiler data. This result is not surprising because well-organized structures that are dynamically and thermally favorable for consistent precipitation had already been generated in the CTRL experiment, which was created by many factors, such as moisture and convergence, and even forcing from the lateral boundaries, which are difficult to break via the assimilation of data obtained from a dense local profiler network.

The accumulated indirect impacts of profiler DA on precipitation forecasts gradually appeared after the third cycle initiated at 0600 UTC of the day. The overprediction in Beijing exceeding $40 \mathrm{~mm}$ by the CTRL experiment was suppressed by the PROF_PASS1 and PROF_PASS2 experiments. To some extent, the assimilation of profiler data improved the forecast of the rainfall center in northeastern Beijing, which is not well predicted in the CTRL. At 0900 UTC, the location and shape of the precipitation event were properly forecasted by all experiments, among which the PROF_PASS2 experiment yielded the best forecasts for the two isolated rainbands located northeast and southeast of Beijing.

\section{c. One-month period cycling experiments}

To investigate the general performance of the profiler DA approach and its impact on forecasts, retrospective 

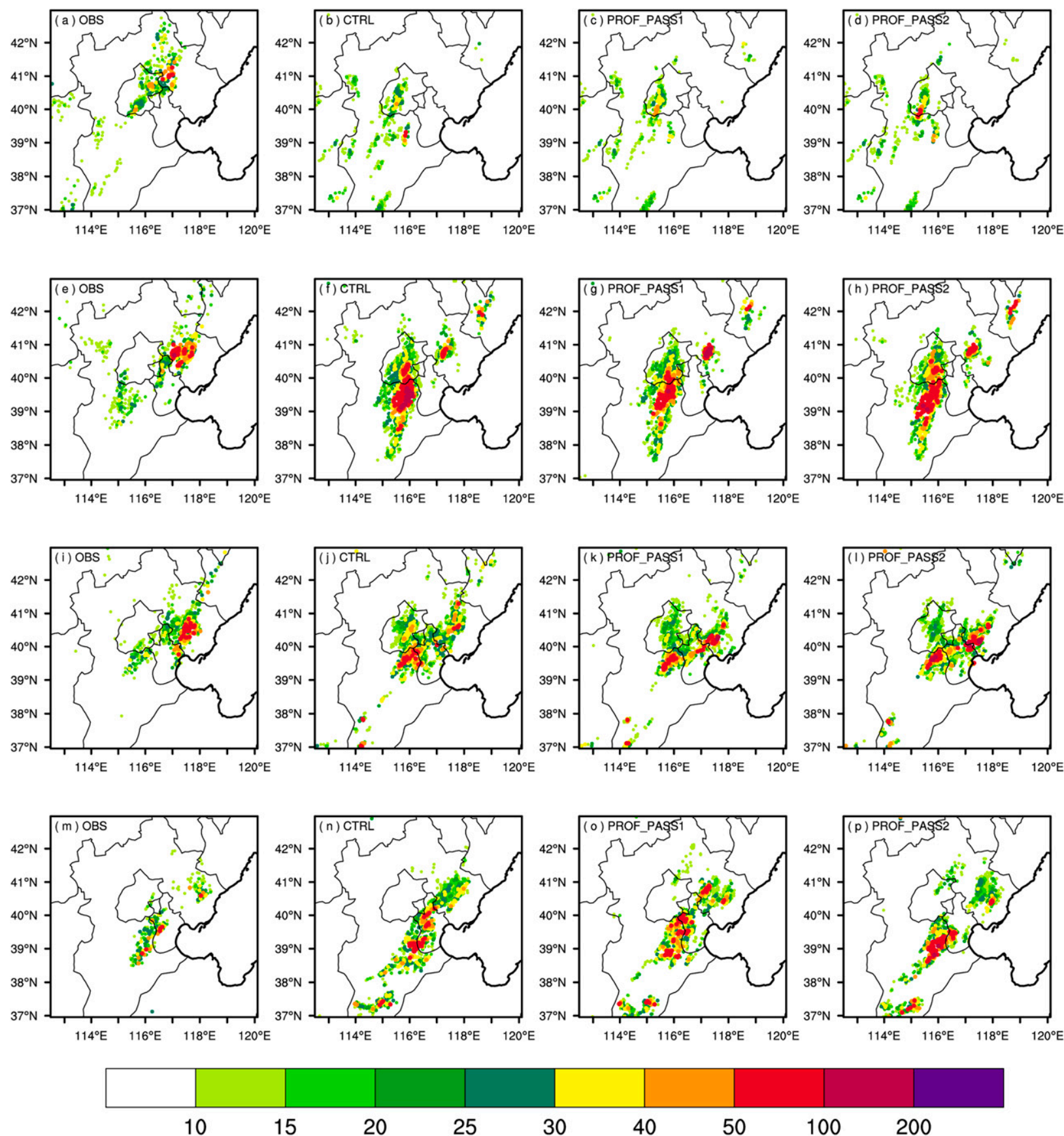

15

$$
20
$$

25

30

40

50

100

200

FIG. 14. The observed rainfall and forecasts of 3-h accumulated precipitation initialized at (a)-(d) 0000, (e)-(h) 0300, (i)-(l) 0600, and (m)-(p) 0900 UTC 17 Jul 2018: (first column) OBS, (second column) CTRL, (third column) PROF_PASS1, and (fourth column) PROF_ PASS2 (mm).

analysis-forecast cycling experiments configured with the CTRL, PROF_PASS1 and PROF_PASS2 schemes are conducted during a 1-month period from 0000 UTC 1 July 2018 to 2100 UTC 31 July 2018. Considering that the radial velocity data are only available in the $3-\mathrm{km}$ domain, the profiler data are only assimilated in domain D02 in all three experiments.

\section{1) VERIFICATION: CONVENTIONAL VARIABLES}

Verification against radiosonde data at 0000 and 1200 UTC and surface observations at 3-h intervals were performed for the forecasts by each retrospective run. In general, the assimilation of profiler data exerted minimal impact on the $10-\mathrm{m}$ wind forecasts, and the domain-averaged RMSE 

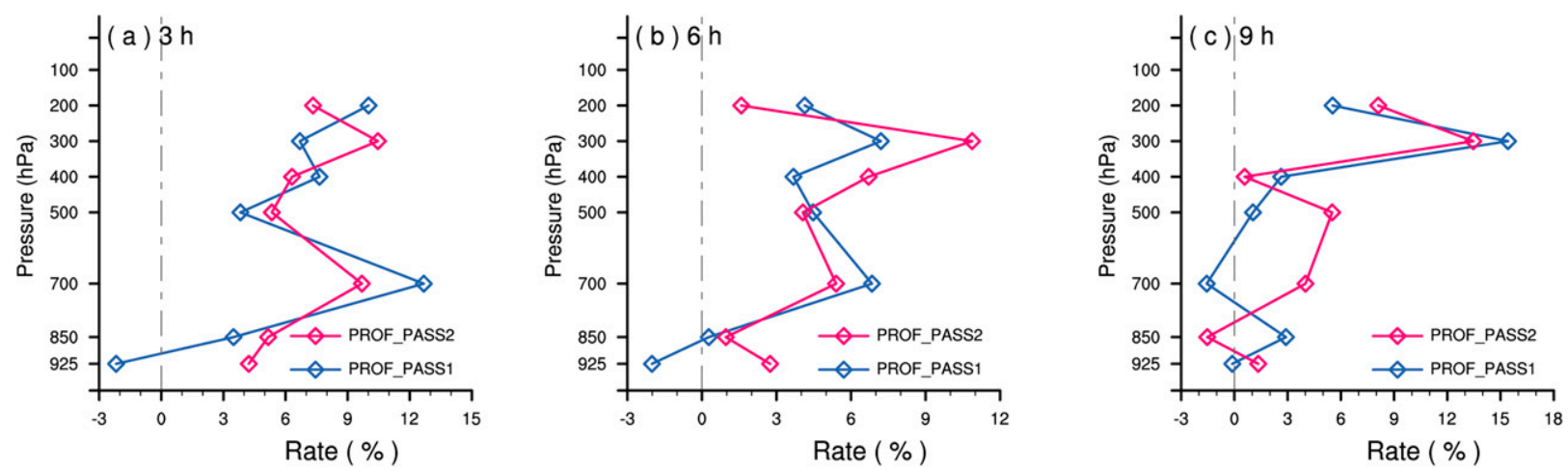

FIG. 15. The averaged vertical profiles of the RMSE improvement rates (\%) between two profiler DA methods and CTRL experiments; PROF_PASS1 (the improvement rate of PROF_PASS1 compared to CTRL; blue) and PROF_PASS2 (the improvement rate of PROF_ PASS2 compared to CTRL; red): (a) 3-, (b) 6-, and (c) 9-h forecasts.

vertical profiles of the PROF_PASS1 and PROF_PASS2 runs from approximately 3 to $9 \mathrm{~h}$ reveal weak error reductions in the upper-air wind forecasts against the CTRL run (not shown). However, when focusing on the Beijing-Tianjin-Hebei region, which contains only four radiosondes, the impact of profiler DA was highlighted with an obvious positive impact percentage against the CTRL (Fig. 15). The assimilation of dense profilers accounts for a maximum error reduction of $16 \%$ at most mandatory levels from 200 to $850 \mathrm{hPa}$. A weak or even negative impact percentage at $925 \mathrm{hPa}$ implies the unsteady effect of wind profiler DA, which is associated with the larger temporal variability of wind disturbances in the lower troposphere. Relatively, the PROF_PASS2 run is superior to the PROF_PASS1 run with a more apparent large and stable improvement percentage.
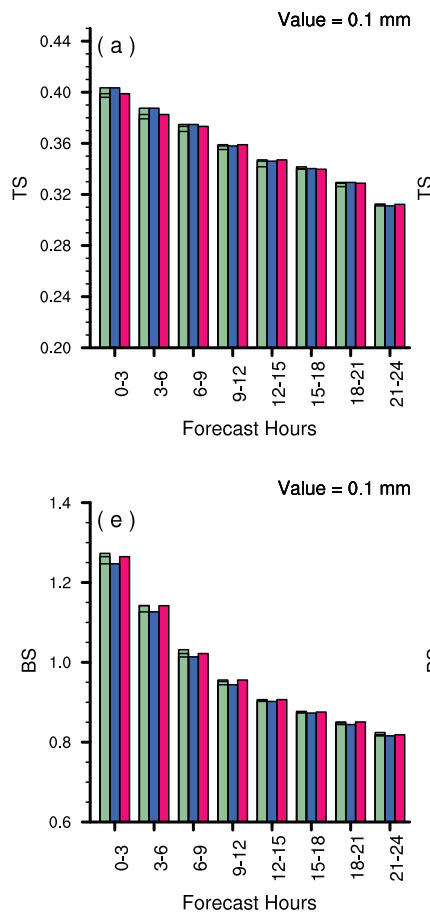

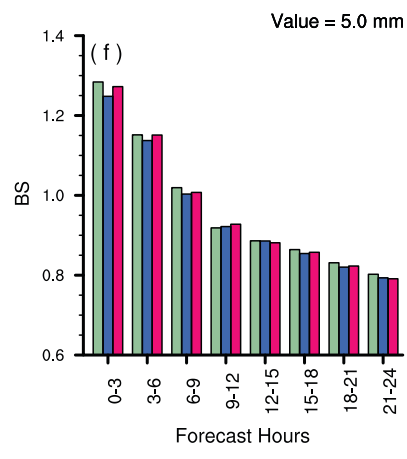

CTRL

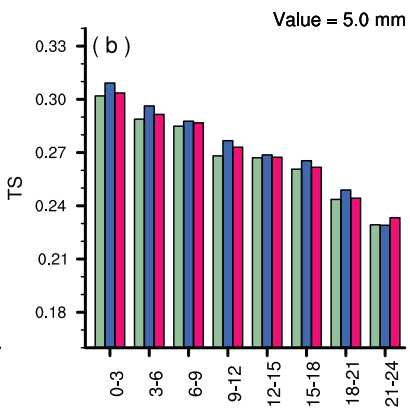

Forecast Hours

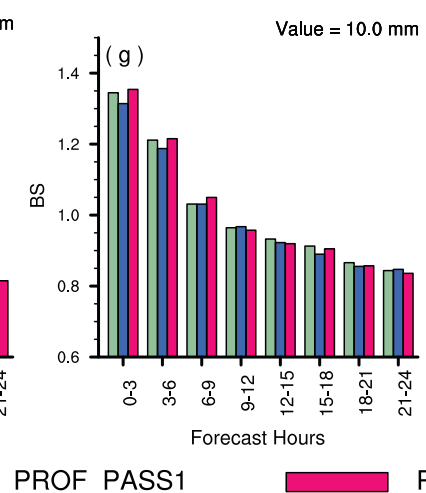

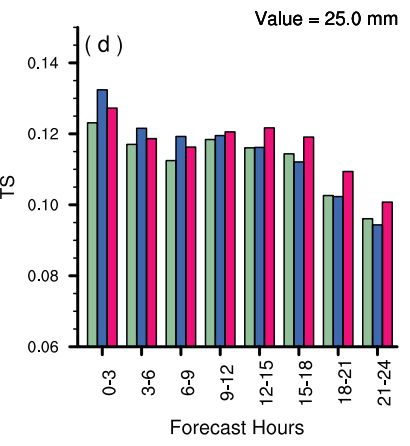

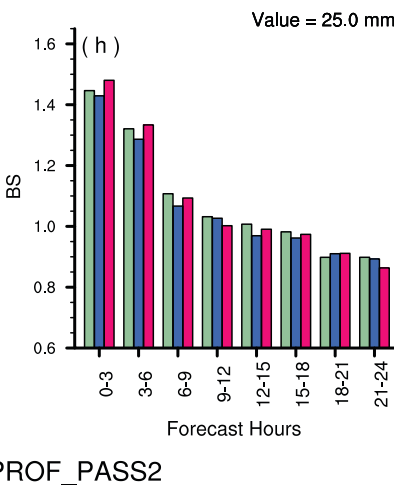

FIG. 16. Average (a)-(d) TS scores and (e)-(h) bias scores for 3-h accumulated precipitation (0-3-, 3-6-, 6-9-, 9-12-, 12-15-, 15-18-, 18-21-, and 21-24-h forecasts, respectively) over different leading times with precipitation thresholds of $0.1,5.0,10.0$, and $25.0 \mathrm{~mm}$ for different experiments CTRL (green), PROF_PASS1 (blue), and PROF_PASS2 (red). 


\section{2) VerificATION: PRECIPITATION}

The precipitation forecasts across all three experiments are evaluated against the AWS rainfall observations. Figure 16 shows the threat scores (TSs) and bias scores (BSs) of all experiments with thresholds of $0.1,5.0,10.0$, and $25.0 \mathrm{~mm}$ for the 3-h accumulated precipitation forecasts. It is encouraging that both of the profiler DA experiments produce higher scores than the CTRL experiment at nearly all thresholds, particularly for heavy rainfall (thresholds of 10.0 and $25.0 \mathrm{~mm}$ ). In regard to the short-range QPFs $(t=3-9 \mathrm{~h})$, the TSs of the PROF_PASS1 experiment are enhanced with lower biases, implying that the assimilation of profiler data in the first pass improves the precipitation forecasts with less overprediction of the rainfall amount and size during the first several forecast hours.

The behaviors of the BSs of the PROF_PASS2 and CTRL experiments are quite similar, indicating that regardless of the assimilation of the profiler observations and radial velocity in Pass II, the overall rainfall forecast size does not change much. The three experiments yielded overestimated precipitation forecasts from $t=0$ to $9 \mathrm{~h}$, as the BSs typically exceeded 1.0, while from $t=9$ to $24 \mathrm{~h}$, precipitation forecasts were underestimated with BSs less than 1.0. This finding suggests that the dynamical and thermal information introduced in the three experiments does not have a smoothing effect in the model forecasts and that the multiscale information cannot be effectively maintained during precipitation forecasting. PROF_PASS2 has slightly higher TS scores, ranging from approximately $1 \%-3 \%$, than the CTRL experiment. This experiment consistently ranks last over the entire 24-h forecast period, which suggests that with the positive influence from the profiler DA approach in Pass II, the forecasted rainfall amounts are steadily improved. The only exception occurs at $t=3 \mathrm{~h}$ for the $25.0-\mathrm{mm}$ threshold, and the higher TS values of the PROF_PASS2 experiment perhaps occur due to rainfall overprediction. It is found that only during the short-term forecast range $(t=3-9 \mathrm{~h})$ does the PROF_PASS1 experiment produce higher TS values than those produced by the PROF_PASS2 experiment, and vice versa for the forecasts from $t=12$ to $24 \mathrm{~h}$. Therefore, considering these results, it is determined that compared to the PROF_PASS1 experiment, the PROF_PASS2 experiment is the preferred strategy for the combined assimilation of profiler and Doppler radar radial winds in terms of obtaining more skillful QPFs.

\section{Summary and discussion}

In this study, the effects of assimilating profiler data obtained from a dense profiler network in northern China with radar radial wind are documented.

First, the profiler observations after performing a two-step profiler QC procedure based on IRMCD outlier detection were determined to be suitably prepared for the subsequent DA. By conducting a series of single- and dual-observation tests on the two typical scenarios of the profiler wind relative to the radar radial velocity, the benefits of the combined assimilation of the two wind observations are displayed.
Specifically, detailed diagnostics are performed to understand the effects of the two assimilation strategies: 1) Strategy I, first assimilate the profiler and conventional data with regular background correlation scalings, and the resulting analysis is then adjusted by assimilating the radar data; 2) Strategy II, both profiler and radar data are considered as storm-scale and are assimilated within the same pass. A precipitation case with a strong LLJ is then selected to evaluate the performance differences between these two strategies. Subsequently, a series of cycling forecasts with/without the assimilation of profiler data is conducted and compared. The main conclusions are summarized as follows:

The IRMCD-based QC procedure has been demonstrated to effectively remove poor-quality profiler stations and outliers. In the 1-month cycling experiments, the observations that passed the QC procedure exhibit Gaussian-like innovations, of which nearly $98 \%-99 \%$ are successfully absorbed by WRFDA, implying that with the established QC procedure, a high profiler data quality is ensured.

Based on the single- and dual-observation tests, the effect of single-radar radial velocity assimilation largely depends on the deviation between the observed environmental direction and the radial wind direction. If radial winds are not consistent with the dominant components of the environmental wind, the actual effects produced by its assimilation would be uncertain, and to some extent, likely negative, because the observed radial winds have a lower dimension than the property (2D or 3D wind) that they are influencing in the analysis. In this case, wind profiler data could provide complementary benefits when assimilated with radial winds. Both assimilation methods of the two different observations with specific tuned factors considerably impact the wind analyses. It is considered that both profilers and radial winds can resolve storm-scale information, thereby the analysis results are optimal under the constraint of assimilating both types of observations with smaller background correlation length in the same assimilation pass. In contrast, the profiler and Doppler radar data must be assimilated separately to adopt different length and variance scales in Strategy I. Thus, the improvement in analysis generated by the assimilation of profiler data is mitigated when it serves as the background for the radial velocity assimilation.

According to the LLJ case study, the combined assimilation yields wind analysis and subsequent forecasts that better conform to the wind profiler data. The improvements suggest that Strategy II using tuned background correlation scalings outperforms Strategy I that defines profilers as synoptic-scale observations. The results of 1-month, updated, cycling forecasting experiments demonstrate that both Strategy I and Strategy II yield improved forecasts in terms of the wind RMSE scores but limited improvement in precipitation forecasts.

As demonstrated by previous studies, it is encouraging that even when assimilated with Doppler radar data, which is critical in convective-scale precipitation forecasts, profiler observations still provide added value. Within the convective-scale assimilation framework, it is more appropriate to assimilate profiler and radar data in the same pass, as the profilers 
primarily sample convection-scale features, while the mutual constraints from both observations are also valuable. When the strategy of profiler and Doppler radar observations are assimilated in turn, the impacts of radar would be overstated as radar data usually comprise the only assimilated observations within the isolated assimilation pass. The combined assimilation of profiler and radar data and co-adjustments of length and variance scales provide corroborating information to further influence analysis and forecasts.

It should be noted that in this study, we mainly examine the supplementary role of wind profilers in the case of singleradar coverage, which suggests that the wind profiler observation network has great value, especially in areas where the Doppler radar network is relatively sparsely deployed and cannot provide overlapped coverage. Owing to the limitation of the Doppler radar detection method, the 3D wind fields retrieved from single-radar radial wind data through a series of hypotheses and approximations would deviate from the ground truth. The benefits yielded by multiradar coverage are notable. However, it is necessary to further examine the radar network layout to ensure that radial wind observation assimilation more completely reflects the real environmental wind field based on the theory and practice of assimilation.

Acknowledgments. This research is sponsored by the National Key Research and Development Project of China (2018YFC1506804).

\section{REFERENCES}

Adachi, A., T. Kobayashi, K. S. Gage, D. A. Carter, L. M. Hartten, W. L. Clark, and M. Fukuda, 2005: Evaluation of three-beam and four-beam profiler wind measurement techniques using a five-beam wind profiler and collocated meteorological tower. $J$. Atmos. Oceanic Technol., 22, 1167-1180, https://doi.org/10.1175/ JTECH1777.1.

Andersson, E., and A. Garcia-Mendez, 2002: Assessment of European wind profiler data, in an NWP context. Tijdschr. Hoger Onderwijs, 20, 202-205.

Angevine, W. M., A. W. Grimsdell, L. M. Hartten, and A. C. Delany, 1998: The Flatland boundary layer experiments. Bull. Amer. Meteor. Soc., 79, 419-432, https://doi.org/10.1175/ 1520-0477(1998)079<0419:TFBLE > 2.0.CO;2.

Barker, D., and Coauthors, 2012: The Weather Research and Forecasting Model's Community Variational/Ensemble Data Assimilation System: WRFDA. Bull. Amer. Meteor. Soc., 93, 831-843, https://doi.org/10.1175/BAMS-D-11-00167.1.

Benjamin, S. G., B. E. Schwartz, E. J. Szoke, and S. E. Koch, 2004: The value of wind profiler data in U.S. weather forecasting. Bull. Amer. Meteor. Soc., 85, 1871-1886, https://doi. org/10.1175/BAMS-85-12-1871.

—, B. D. Jamison, W. R. Moninger, S. R. Sahm, B. E. Schwartz, and T. W. Schlatter, 2010: Relative short-range forecast impact from aircraft, profiler, radiosonde, VAD, GPS-PW, METAR, and mesonet observations via the RUC hourly assimilation cycle. Mon. Wea. Rev., 138, 1319-1343, https://doi.org/10.1175/2009MWR3097.1.

Bouttier, F., 2001: The use of profiler data at ECMWF. Meteor. Z., 10, 497-510, https://doi.org/10.1127/0941-2948/2001/0010-0497.
Calpini, B., and Coauthors, 2011: Ground-based remote sensing profiling and numerical weather prediction model to manage nuclear power plants meteorological surveillance in Switzerland. Atmos. Meas. Tech., 4, 1617-1625, https://doi.org/10.5194/amt-41617-2011.

Chen, F., and J. Dudhia, 2001: Coupling an advanced land surface-hydrology model with the Penn State-NCAR MM5 modeling system. Part I: Model implementation and sensitivity. Mon. Wea. Rev., 129, 569-585, https://doi.org/10.1175/ 1520-0493(2001)129<0569:CAALSH > 2.0.CO;2.

_, X. Liang, and H. Ma, 2017: Application of IVAP-based observation operator in radar radial velocity assimilation: The case of Typhoon Fitow. Mon. Wea. Rev., 145, 4187-4203, https://doi.org/10.1175/MWR-D-17-0002.1.

Chen, M., and Coauthors, 2009: A WRF-based rapid updating cycling forecast system of BMB and its performance during the summer and Olympic Games 2008. WMO Symp. on Nowcasting, Whistler, BC, Canada, WMO, 30 pp.

—, M. Chen, and Y. Fan, 2014: The real-time radar radial velocity 3DVar assimilation experiments for application to an operational forecast model in North China. Acta Meteor. Sin., 72, 658-677.

Dong, J., M. Xue, and K. Droegemeier, 2011: The analysis and impact of simulated high-resolution surface observations in addition to radar data for convective storms with an ensemble Kalman filter. Meteor. Atmos. Phys., 112, 41-61, https:// doi.org/10.1007/s00703-011-0130-3.

Gao, J., and D. J. Stensrud, 2014: Some observing system simulation experiments with a hybrid 3DEnVAR system for stormscale radar data assimilation. Mon. Wea. Rev., 142, 33263346, https://doi.org/10.1175/MWR-D-14-00025.1.

Gustafsson, N., and Coauthors, 2018: Survey of data assimilation methods for convective-scale numerical weather prediction at operational centres. Quart. J. Roy. Meteor. Soc., 144, 12181256, https://doi.org/10.1002/qj.3179.

Hong, S.-Y., Y. Noh, and J. Dudhia, 2006: A new vertical diffusion package with an explicit treatment of entrainment processes. Mon. Wea. Rev., 134, 2318-2341, https://doi.org/10. 1175/MWR3199.1.

Hu, M., M. Xue, J. Gao, and K. Brewster, 2006: 3DVAR and cloud analysis with WSR-88D Level-II data for the prediction of Fort Worth tornadic thunderstorms. Part II: Impact of radial velocity analysis via 3DVAR. Mon. Wea. Rev., 134, 699-721, https://doi.org/10.1175/MWR3093.1.

Iacono, M. J., J. S. Delamere, E. J. Mlawer, M. W. Shephard, S. A. Clough, and W. D. Collins, 2008: Radiative forcing by long-lived greenhouse gases: Calculations with the AER radiative transfer models. J. Geophys. Res., 113, D13103, https:// doi.org/10.1029/2008JD009944.

Ishihara, M., Y. Kato, T. Abo, K. Kobayashi, and Y. Izumikawa, 2006: Characteristics and performance of the operational wind profiler network of the Japan Meteorological Agency. J. Meteor. Soc. Japan, 84, 1085-1096, https://doi.org/10.2151/ jmsj.84.1085.

Kain, J. S., 2004: The Kain-Fritsch convective parameterization: An update. J. Appl. Meteor., 43, 170-181, https://doi.org/10. 1175/1520-0450(2004)043<0170:TKCPAU>2.0.CO;2.

- , and Coauthors, 2010: Assessing advances in the assimilation of radar data and other mesoscale observations within a collaborative forecasting-research environment. Wea. Forecasting, 25, 1510-1521, https://doi.org/10.1175/2010WAF2222405.1.

Lippi, D. E., J. R. Carley, and D. T. Kleist, 2019: Improvements to the assimilation of Doppler radial winds for convection- 
permitting forecasts of a heavy rain event. Mon. Wea. Rev., 147, 3609-3632, https://doi.org/10.1175/MWR-D-18-0411.1.

Michelson, S. A., and N. L. Seaman, 2000: Assimilation of NEXRAD-VAD winds in summertime meteorological simulations over the northeastern United States. J. Appl. Meteor., 39, 367-383, https://doi.org/10.1175/1520-0450(2000)039<0367: AONVWI $>2.0 . \mathrm{CO} ; 2$.

Montmerle, T., and C. Faccani, 2009: Mesoscale assimilation of radial velocities from Doppler radars in a preoperational framework. Mon. Wea. Rev., 137, 1939-1953, https://doi.org/ 10.1175/2008MWR2725.1.

Rennie, S. J., S. L. Dance, A. J. Illingworth, S. P. Ballard, and D. Simonin, 2011: 3D-Var assimilation of insect-derived Doppler radar radial winds in convective cases using a high-resolution model. Mon. Wea. Rev., 139, 1148-1163, https://doi.org/10. 1175/2010MWR3482.1.

Schenkman, A. D., M. Xue, A. Shapiro, K. Brewster, and J. Gao, 2011: Impact of CASA radar and Oklahoma Mesonet data assimilation on the analysis and prediction of tornadic mesovortices in an MCS. Mon. Wea. Rev., 139, 3422-3445, https:// doi.org/10.1175/MWR-D-10-05051.1.

Simonin, D., S. P. Ballard, and Z. Li, 2014: Doppler radar radial wind assimilation using an hourly cycling 3DVar with a 1.5 $\mathrm{km}$ resolution version of the Met Office Unified Model for nowcasting. Quart. J. Roy. Meteor. Soc., 140, 2298-2314, https://doi.org/10.1002/qj.2298.

Skamarock, W. C., and Coauthors, 2008: A description of the Advanced Research WRF version 3. NCAR Tech. Note NCAR/ TN-475+STR, 113 pp., https://doi.org/10.5065/D68S4MVH.

St-James, J. S., and S. Laroche, 2005: Assimilation of wind profiler data in the Canadian Meteorological Centre's analysis systems. J. Atmos. Oceanic Technol., 22, 1181-1194, https://doi. org/10.1175/JTECH1765.1.

Sugimoto, S., N. A. Crook, J. Sun, Q. Xiao, and D. M. Barker, 2009: An examination of WRF 3DVAR radar data assimilation on its capability in retrieving unobserved variables and forecasting precipitation through observing system simulation experiments. Mon. Wea. Rev., 137, 4011-4029, https://doi.org/ 10.1175/2009MWR2839.1.

Sun, J., H. Wang, W. Tong, Y. Zhang, C.-Y. Lin, and D. Xu, 2016: Comparison of the impacts of momentum control variables on high-resolution variational data assimilation and precipitation forecasting. Mon. Wea. Rev., 144, 149-169, https:// doi.org/10.1175/MWR-D-14-00205.1.

Thompson, G., P. R. Field, R. M. Rasmussen, and W. D. Hall, 2008: Explicit forecasts of winter precipitation using an improved bulk microphysics scheme. Part II: Implementation of a new snow parameterization. Mon. Wea. Rev., 136, 50955115, https://doi.org/10.1175/2008MWR2387.1.

Tong, M., and M. Xue, 2005: Ensemble Kalman filter assimilation of Doppler radar data with a compressible nonhydrostatic model: OSS experiments. Mon. Wea. Rev., 133, 1789-1807, https://doi.org/10.1175/MWR2898.1.

Tong, W., G. Li, J. Sun, X. Tang, and Y. Zhang, 2016: Design strategies of an hourly update 3DVAR data assimilation system for improved convective forecasting. Wea. Forecasting, 31, 1673-1695, https://doi.org/10.1175/WAF-D-16-0041.1.

Wang, C., Y. Chen, M. Chen, and J. Shen, 2020: Data assimilation of a dense wind profiler network and its impact on convective forecasting. Atmos. Res., 238, 104880, https://doi.org/10.1016/j. atmosres.2020.104880.

Weygandt, S. S., A. Shapiro, and K. K. Droegemeier, 2002: Retrieval of model initial fields from single-Doppler observations of a supercell thunderstorm. Part I: Single-Doppler velocity retrieval. Mon. Wea. Rev., 130, 433-453, https://doi. org/10.1175/1520-0493(2002)130<0433:ROMIFF $>2.0$. CO;2.

Xiao, Q., and J. Sun, 2007: Multiple-radar data assimilation and short-range quantitative precipitation forecasting of a squall line observed during IHOP_2002. Mon. Wea. Rev., 135, 3381-3404, https://doi.org/10.1175/MWR3471.1.

— , Y.-H. Kuo, J. Sun, W.-C. Lee, E. Lim, Y.-R. Guo, and D. M. Barker, 2005: Assimilation of Doppler radar observations with a regional 3DVAR system: Impact of Doppler velocities on forecasts of a heavy rainfall case. J. Appl. Meteor., 44, 768-788, https://doi.org/10.1175/JAM2248.1.

Xie, Y., S. Koch, J. McGinley, S. Albers, P. E. Bieringer, M. Wolfson, and M. Chan, 2011: A space-time multiscale analysis system: A sequential variational analysis approach. Mon. Wea. Rev., 139, 1224-1240, https://doi.org/10.1175/2010MWR3338.1.

Xu, Q., W. Li, J. Gao, Q. Zhao, K. Nai, and S. Liu, 2016: Multistep variational data assimilation: Important issues and a spectral approach. Tellus, 68A, 31110, https://doi.org/10.3402/ tellusa.v68.31110

Zhang, X., Y. Luo, Q. Wan, W. Ding, and J. Sun, 2016: Impact of assimilating wind profiling radar observations on convectionpermitting quantitative precipitation forecasts during SCMREX. Wea. Forecasting, 31, 1271-1292, https://doi.org/ 10.1175/WAF-D-15-0156.1.

Zhang, Y., M. Chen, and J. Zhong, 2017: A quality control method for wind profiler observations toward assimilation applications. J. Atmos. Oceanic Technol., 34, 1591-1606, https://doi.org/10.1175/JTECH-D-16-0161.1. 